\title{
Linear and nonlinear winter atmospheric responses to extreme phases of low frequency Pacific sea surface temperature variability
}

\author{
Dandan $\mathrm{Cao}^{1}$ · Qigang $\mathrm{Wu}^{1,2}$. Aixue $\mathrm{Hu}^{3}$. Yonghong Yao ${ }^{1}$. Shizuo Liu ${ }^{1}$ Steven R. Schroeder ${ }^{4}$ Fucheng Yang ${ }^{1}$
}

Received: 7 January 2017 / Accepted: 3 January 2018 / Published online: 23 February 2018

(c) The Author(s) 2018. This article is an open access publication

\begin{abstract}
This study examines Northern Hemisphere winter (DJFM) atmospheric responses to opposite strong phases of interdecadal (low frequency, LF) Pacific sea surface temperature (SST) forcing, which resembles El Niño-Southern Oscillation (ENSO) on a longer time scale, in observations and GFDL and CAM4 model simulations. Over the Pacific-North America (PNA) sector, linear observed responses of 500-hPa height (Z500) anomalies resemble the PNA teleconnection pattern, but show a PNA-like nonlinear response because of a westward Z500 shift in the negative (LF-) relative to the positive LF (LF+) phase. Significant extratropical linear responses include a North Atlantic Oscillation (NAO)-like Z500 anomaly, a dipole-like Z500 anomaly over northern Eurasia associated with warming over mid-high latitude Eurasia, and a Southern Annular anomaly pattern associated with warming in southern land areas. Significant nonlinear Z500 responses also include a NAO-like anomaly pattern. Models forced by LF+ and LF- SST anomalies reproduce many aspects of observed linear and nonlinear responses over the Pacific-North America sector, and linear responses over southern land, but not in the North AtlanticEuropean sector and Eurasia. Both models simulate PNA-like linear responses in the North Pacific-North America region similar to observed, but show larger PNA-like LF+ responses, resulting in a PNA nonlinear response. The nonlinear PNA responses result from both nonlinear western tropical Pacific rainfall changes and extratropical transient eddy feedbacks. With LF tropical Pacific forcing only (LFTP+ and LFTP-, climatological SST elsewhere), CAM4 simulates a significant NAO response to LFTP-, including a linear negative and nonlinear positive NAO response.
\end{abstract}

Keywords Interdecadal variability $\cdot$ Low frequency $\cdot$ Sea surface temperature $\cdot$ Atmospheric response $\cdot$ Nonlinear

\section{Introduction}

Studies show robust linear and nonlinear asymmetric atmospheric responses in Pacific and North America winter (December-March, DJFM) to opposite phases of El Niño-Southern Oscillation (ENSO) sea surface temperature (SST) forcing in observations and simulations (e.g. Pitcher et al. 1988; Kushnir and Lau 1992; Hoerling et al.

Qigang Wu

qigangwu@fudan.edu.cn

1 School of Atmospheric Sciences, Nanjing University, Nanjing 210023, Jiangsu, China

2 Present Address: Institute of Atmospheric Sciences, Fudan University, Shanghai 200433, China

3 National Center for Atmospheric Research, Boulder, CO, USA

4 Department of Atmospheric Sciences, Texas A\&M University, College Station, TX, USA
1997, 2001; Montroy et al. 1998; Gershunov and Barnett 1998; DeWeaver and Nigam 2002; Lin et al. 2007; Wu et al. 2010; Zhang et al. 2011, 2014). The linear PNA response to ENSO events has been extensively investigated (e.g., Horel and Wallace 1981), and involves a poleward-propagating Rossby wave train excited by tropical convection (Hoskins and Karoly 1981; Simmons 1982; Sardeshmukh and Hoskins 1988). Nonlinearity includes both differing anomaly magnitudes (or asymmetry) with opposite deviations of a defining index, and geographical changes in anomaly patterns. Hoerling et al. (1997) find that there is a shift of about $35^{\circ}$ eastward in the upper-atmospheric response over the equatorial Pacific in El Niño relative to La Niña, and attribute this to differences in tropical deep convection and diabatic heating. In addition, a significant nonlinear response to ENSO is also reported in the North Atlantic and European regions, with a response resembling a positive North Atlantic Oscillation (NAO) during both La Niña and El Niño events (PozoVazquez et al. 2001; Lin and Derome 2004; Wu and Hsieh 
2004; Wu et al. 2005), although the associated mechanism is not clear (Lin et al. 2007). Some studies also find a link between warm ENSO events and the negative phase of the wintertime NAO, in which the polar stratosphere plays a significant role through wave-mean flow interactions (Bronnimann 2007; Ineson and Scaife 2009; Cagnazzo and Manzini 2009; Bell et al. 2009; Fletcher and Kushner 2010, 2011).

Zhang et al. (1997) described the 1976-1977 climate shift as resembling an interdecadal scale transition from La Niña to El Niño, and in a 1900-1993 SST record found another El Niño-like phase in 1925-1942 in the tropical and extratropical northern Pacific. They filtered Pacific SST variability into ENSO "interannual" (about $<6$ years) and ENSO-like "interdecadal" (about $\geq 6$ years) components. Empirical orthogonal functions (EOFs) of both time series show that, compared to ENSO, interdecadal ENSO-like SST anomalies are smaller but extend farther from the equator in the eastern Pacific and are stronger in the extratropical North Pacific. There is no absolute cutoff between time scales so the $\geq 6$ year scale is often called low-frequency (LF). Mantua et al. (1997) called the ENSO-like mode the Pacific Decadal Oscillation (PDO) and defined a PDO index based on the November-March average Pacific SST anomaly north of $20^{\circ}$ N. Others (e.g., Power et al. 1999; Salinger et al. 2001; Arblaster et al. 2002; Deser et al. 2004; Newman et al. 2003, 2016) found in-phase SST anomalies in the extratropical South Pacific and North Pacific, indicating that PDO is only part of a single Pacific-wide phenomenon called the Interdecadal Pacific Oscillation (IPO). In Folland et al. (2002), annual IPO and PDO index values are almost identical from 1900 to 1999.

The PDO and IPO have significant worldwide impacts (Mantua et al. 1997; Gershunov and Barnett 1998; Power et al. 1999; McCabe and Dettinger 1999; Gershunov and Cayan 2003; Andreoli and Kayano 2005; Wang et al. 2008, 2014). PDO/IPO SST variability has recently been noted as particularly important for explaining observed decadal changes in global mean surface air temperature (SAT), such as the apparent hiatus in atmospheric warming since 1998 (e.g., Meehl et al. 2013; Kosaka and Xie 2013; Trenberth et al. 2014), so better knowledge of PDO/IPO teleconnections should improve decadal prediction over North and South America, Asia, Africa, and Australia (Power et al. 1999; Deser et al. 2004; Meehl and Hu 2006; Smith et al. 2012).

The main purpose here is to examine the linearity and nonlinearity of atmospheric responses to strong positive and negative LF phases of Pacific SST anomalies in Northern Hemisphere (NH) winter (December-March, or DJFM) using observational and simulated datasets. Simulated datasets include outputs from two models forced by Pacific SST anomalies filtered to retain LF scales. Most researchers isolate decadal-scale climate signals by compositing climate anomalies or applying linear regression to anomaly fields with respect to an IPO/PDO index (e.g., Mantua et al. 1997; Dong and Dai 2015). A positive IPO or PDO index is often called a warm phase (e.g., Schubert et al. 2009) due to warm anomalies in the largest center of interest. Composites of circulation anomalies for strong positive and negative IPO phases show considerable asymmetries in fields of sea level pressure (SLP) and Z500 (Dai 2013; Dong and Dai 2015; Henley et al. 2015), indicating nonlinear atmospheric responses to IPO positive and negative epochs, but there has been little research on the specific nature of this nonlinearity.

Many studies investigate the impacts of PDO or IPO using empirically-derived anomalies of atmospheric fields in observations and simulations (e.g., Zhang et al. 1997; Mantua et al. 1997; Power et al. 1999; Meehl and Hu 2006; Meehl et al. 2013; Dai 2013). Another purpose of this study is to examine simulated winter atmospheric responses to extreme phases of LF Pacific SST variability using atmospheric general circulation models (AGCMs). We first assess the linearity and nonlinearity of atmospheric responses to strong (or moderate) opposite LF phases in observations, and then examine the corresponding model-simulated tropical and extratropical atmospheric responses to strong opposite LF scenarios. This paper is organized as follows. Data and methods are outlined in Sect. 2. The results from observational analysis and simulations are presented in Sect. 3 and 4 , respectively. A summary and conclusions are provided in Sect. 5.

\section{Datasets and methods}

The forcing pattern of LF Pacific SST variability is from Schubert et al. (2009) (available at https://gmao.gsfc.nasa. gov/research/clivar_drought_wg/) and was produced as follows. First, global monthly gridded SST anomalies from the HadISST dataset (Rayner et al. 2003) are updated to cover 1901-2016, and are filtered by successive centered 25 and 37 -month moving averages (this filtering removes 30 months from each end of the original time series) to extract the LF variability on the time scale of approximately $\geq 6$ years (Zhang et al. 1997). The LF filtered data covers July 1903-June 2014, so where each DJFM winter is referred to by the year when the winter ends, we analyze 111 winters from 1904 to 2014 containing 444 months. Second, a rotated EOF (REOF) analysis was performed on the gridded LF SST anomalies. While the global SST trend is the first REOF (LF REOF1) and its associated principal component time series (LF PC1), this study is concerned with the second mode (LF REOF2 and PC2), which is the decadal Pacific mode shown in Fig. 1. Figure 1a (Fig. A1 in Schubert et al. 2009) shows a meridionally extensive pan-Pacific pattern of variability, with substantial mid-latitude amplitude that in the 


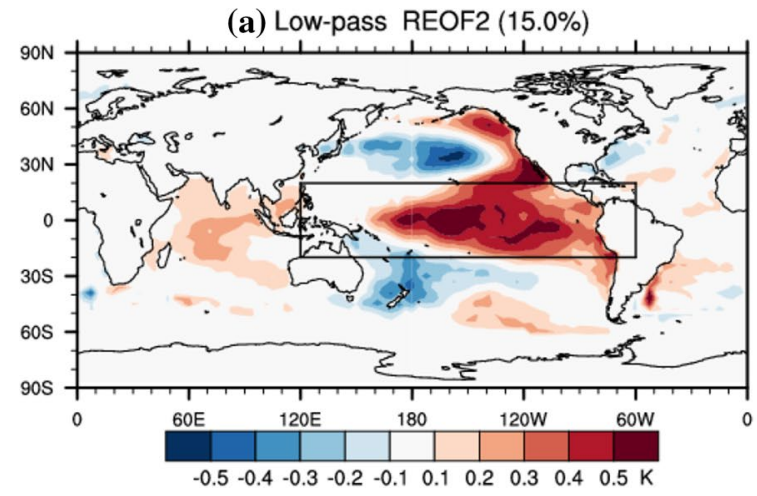

Fig. 1 a The second rotated EOF (REOF2) of low-pass-filtered (time scales greater than 6 year) observed monthly global SST anomalies based on data from July 1903 to June 2002 (Schubert et al. 2009), and $\mathbf{b}$ the associated PC index (PC2) updated to cover July 1903-June 2014. The source for data in this figure is HadISST, low pass filtered

NH resembles the PDO (Zhang et al. 1997). The PC2 time series of monthly LF Pacific SST index values is calculated by projecting the LF filtered grids onto the REOF2 mode in Fig. 1a (the Schubert et al. (2009) REOF2 mode is used here for comparability with model runs described below). Figure $1 \mathrm{~b}$ shows the LF PC2 time series from July 1903 to June 2014

We also use the following gridded monthly (not LF filtered) observational datasets starting with 1903: Z500 and SLP from the Twentieth Century Reanalysis (V2c) (Compo et al. 2011), the NOAA "Merged Air Land and sea surface temperature (SST) Anomalies" (MLOST) dataset (Smith et al. 2008; now referred to as the NOAA Global Surface Temperature dataset), and the Global Precipitation Climatology Centre (GPCC) dataset (Schneider et al. 2013). These datasets are provided by NOAA/OAR/ESRL PSD at http://www.esrl.noaa.gov/psd/. Because the Twentieth Century Reanalysis does not assimilate any upper air data (for consistency through the whole period) but constructs upper air data fields using its model, we use the NCEP/NCAR Reanalysis (Kalnay et al. 1996), provided by https://www. esrl.noaa.gov/psd/data/gridded/data.ncep.reanalysis.html, starting 1948 for additional analyses. For each variable, we composite surface and upper-level atmospheric anomalies for the strong positive and negative LF months in DJFM to obtain the climate response to strong LF phases. Strong LF phases include months with index values $>1.25$ (strong positive, $\mathrm{LF}+$ ) and $<-1.25$ (strong negative, $\mathrm{LF}-$ ), totaling $49 \mathrm{LF}+$ and $57 \mathrm{LF}-$ months out of 444, including 22 LF+ and 53 LF- months in DJFM winters 1949-2014. Four maps for any variable show climate responses (anomalies for composite LF+ months, and for composite LF- months), the linear or symmetric component of the response $(\mathrm{LF}+$ minus LF- difference), and the nonlinear or asymmetric response $(\mathrm{LF}+$ plus LF-). Statistical significance of the observed (b) Low-pass PC2

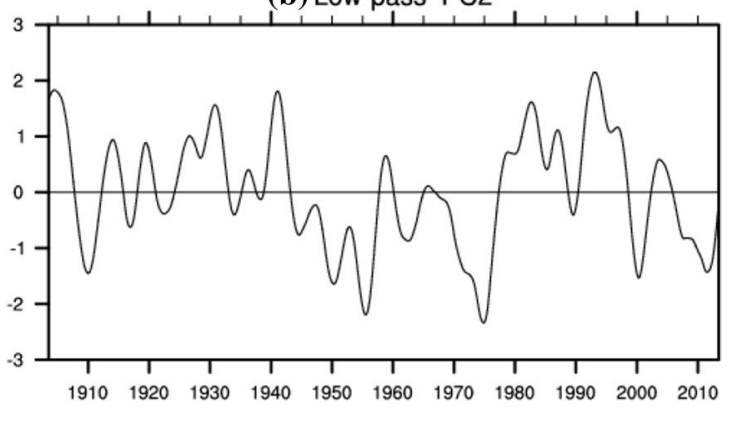

as stated in the text before performing the REOF analysis. The rectangular box in a indicates the Tropical Pacific region where the LFTP experiment with the CAM4 model (see Sect. 4.2) prescribes nonzero LF SST anomalies only in that region

strong LF phase signals is assessed using a standard twotailed difference of means Student's t test (von Storch and Zwiers 1999). In Fig. 1b, the low-pass filtered time series does have a very large lagged autocorrelation. However, we use unfiltered SAT, Z500 and precipitation monthly grids in the composite analysis in Figs. 2, 3 and 4, and the monthto-month lagged autocorrelation is small for these $\mathrm{NH}$ winter atmospheric fields (absolute values less than 0.20). The effective number of degrees of freedom for statistical significance estimated by considering the lagged autocorrelation of these atmospheric fields (Bretherton et al. 1999) is very close to $\mathrm{N}-1$ where $\mathrm{N}$ is the number of strong LF months (between 22 and 57, stated above).

Simulation datasets are outputs of idealized experiments forced with IPO/PDO-like low frequency Pacific SST variability from two independent Atmospheric General Circulation Models (AGCMs). Forcing scenarios and the first set of model runs are selected from a project coordinated by the U.S. Climate Variability and Predictability (CLIVAR) working group on drought (Schubert et al. 2009). Those model runs were performed by NOAA Geophysical Fluid Dynamics Laboratory (GFDL) using their Atmospheric Model version 2.1 (GFDL_AM2.1, available at ftp://gmaoftp.gsfc. nasa.gov/pub/data/clivar_drought_wg/GFDL/), with 17 vertical levels and a horizontal resolution of $1.9^{\circ}$ of latitude by $2.5^{\circ}$ of longitude (Delworth et al. 2006). While the Schubert et al. (2009) project included runs from four other models, only the GFDL model runs are suitable for this study, so we perform runs with the same forcing scenarios using a second model, National Center for Atmospheric Research (NCAR) Community Atmosphere Model version 4 (CAM4), with 26 vertical levels and a T42 horizontal resolution, equivalent to $2.8^{\circ}$ latitude $\times 2.8^{\circ}$ longitude (Neale et al. 2013). The observed and simulated datasets are linearly interpolated on a $2.5^{\circ}$ or $5^{\circ}$ longitude-latitude grid for analysis. 
(a) OBS SAT 1949-2014 (LF+)

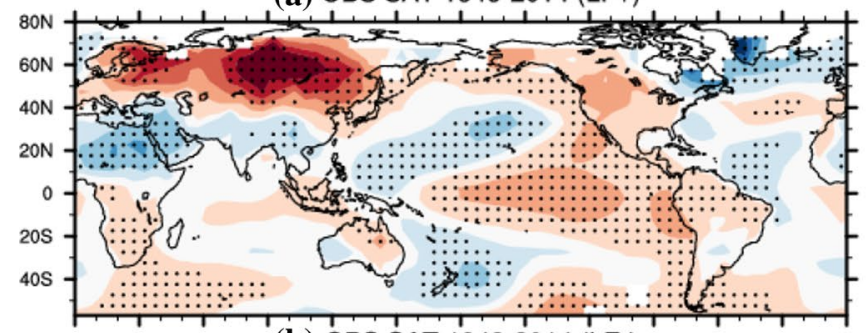

(b) OBS SAT 1949-2014 (LF-)

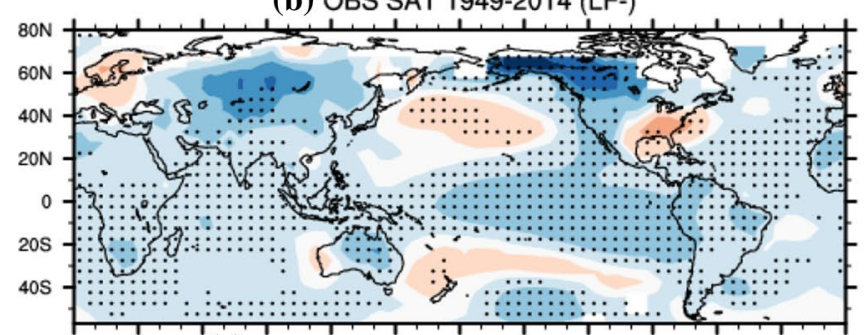

(c) OBS SAT 1949-2014 (LF+ minus LF-)

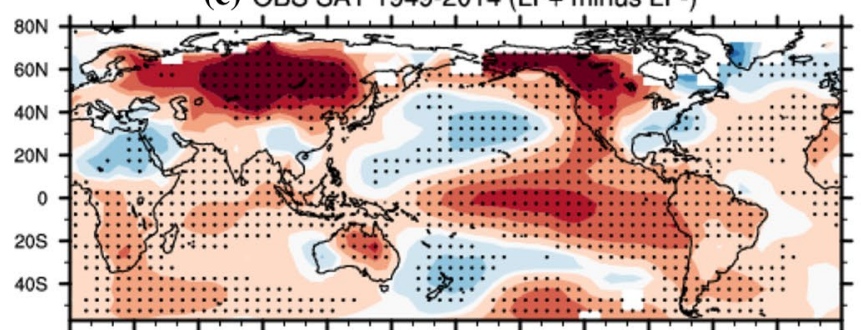

(d) OBS SAT 1949-2014 (LF+ plus LF-)

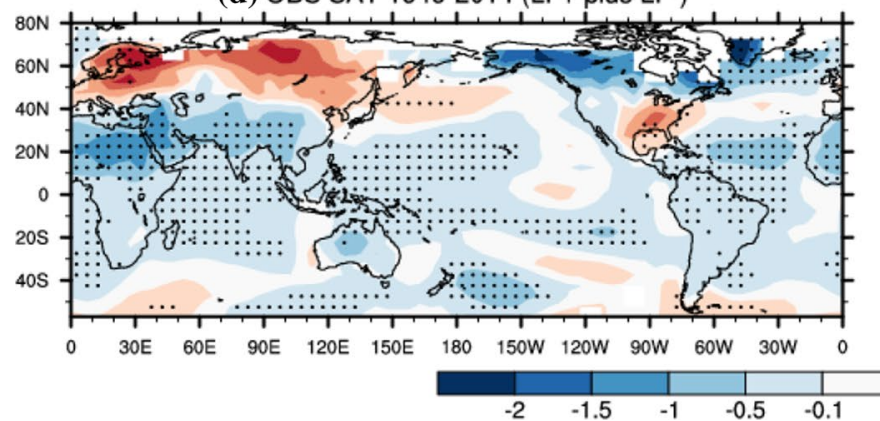

$-2 \quad-1.5$

Fig. 2 Composites of the monthly DJFM observed surface temperature anomalies (SAT over land, SST over oceans, K) from the NOAA GST for extreme phases of (a, e) positive and $\mathbf{b}, \mathbf{f}$ negative LF periods in winter 1949-2014 (left column), 1904-2014 (right column). c, $\mathbf{g}$ Linear component of surface air temperature anomalies as esti-

The following three simulations were performed with the same forcing using each model, as described by Schubert et al. (2009). Each model run is forced with repeating annual cycles of monthly SST and sea ice concentration (SIC) forcing, and the duration of each run is 60 years for GFDL and 210 years for CAM4. After a 10-year spinup, the last 50 years (200 DJFM simulation months) in GFDL and 200 years (800 months) in CAM4 are analyzed. For each model, a climatological (CLM) control simulation uses 1901-2004 monthly climatological SST and SIC forcing (Rayner et al. 2003). The other two simulations are forced (e) OBS SAT 1904-2014 (LF+)

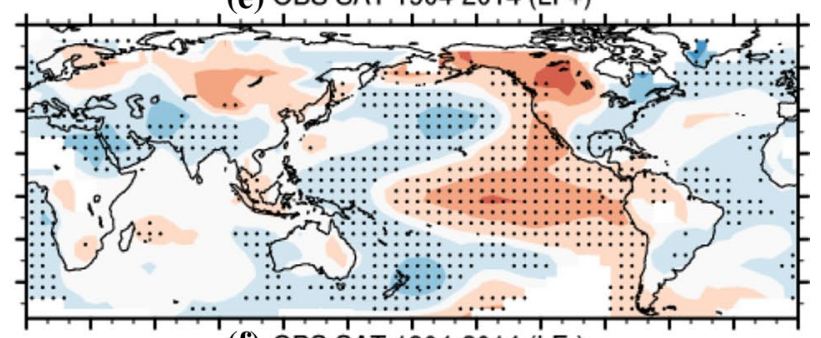

(f) OBS SAT 1904-2014 (LF-)

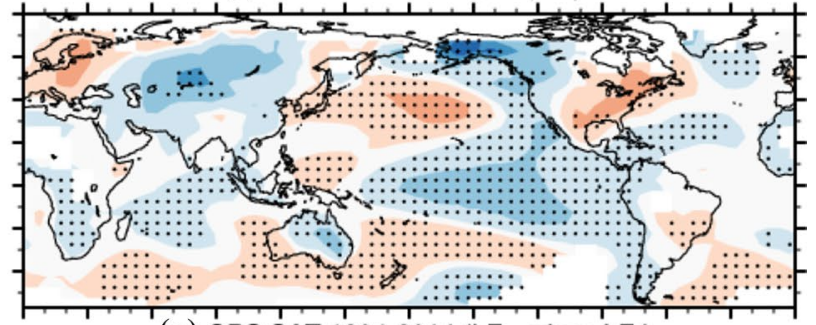

(g) OBS SAT 1904-2014 (LF+ minus LF-)

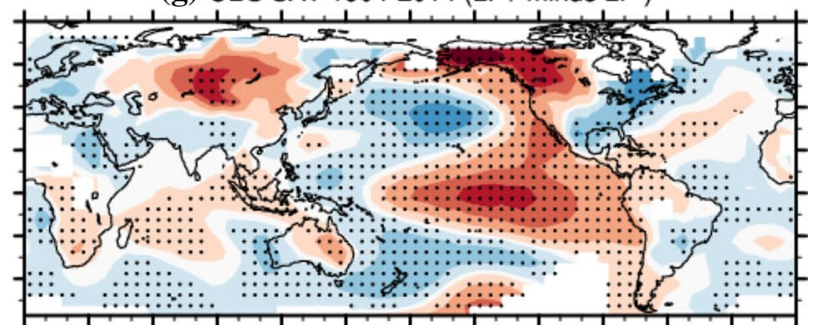

(h) OBS SAT 1904-2014 (LF+ plus LF-)

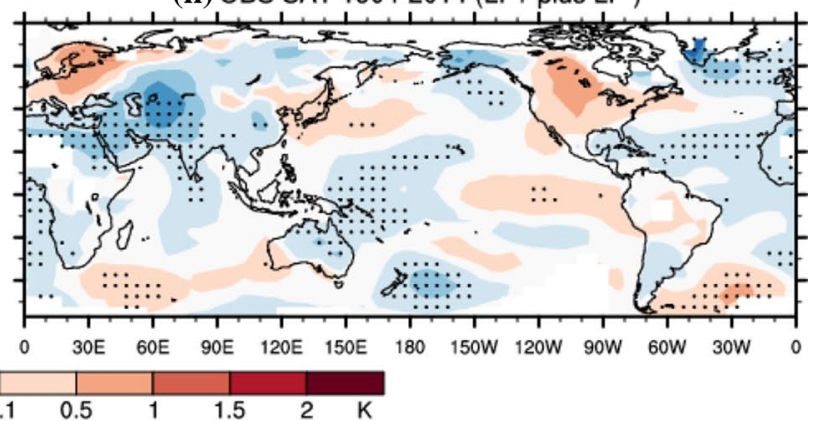

mated by the difference (a) minus (b) or (e) minus (f). d, h honlinear component of surface temperature anomalies, as estimated by the sum (a) plus (b) or (e) plus (f). The black dots denote local statistical significance of values at the $95 \%$ confidence level

with LF SST variability, specifically monthly CLM SST plus the REOF2 anomaly pattern in Fig. 1a multiplied by either +2 (LF strong positive, or the LF+ simulation) or -2 (LF strong negative, or LF-) to emphasize the influence of strong IPO/PDO-like SST patterns. Note that LF+ and $\mathrm{LF}-$ simulation forcings correspond to a constant $\mathrm{PC} 2$ value of +2 or -2 (anomalies are constant through the year), and are slightly stronger than the average of observed LF+ and LF- composites of all months with PC2 magnitudes $\geq 1.25$ or $\leq-1.25$. The CLM run from GFDL_AM2.1 is the PnAn run in Table 1 of Schubert et al. (2009). These GFDL runs 
(a) NCEP Z500 1949-2014 (LF+)

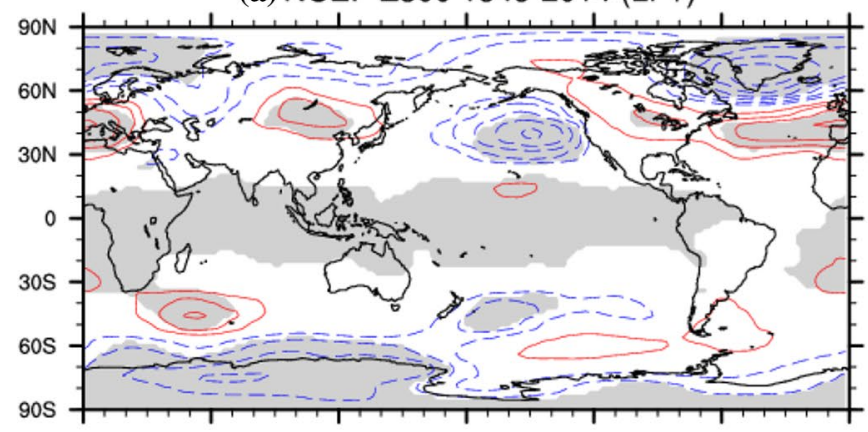

(b) NCEP Z500 1949-2014 (LF-)

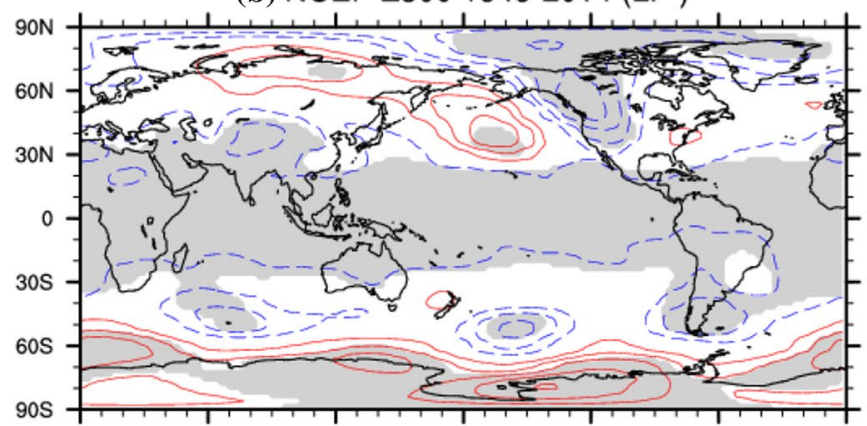

(c) NCEP Z500 1949-2014 (LF+ minus LF-)

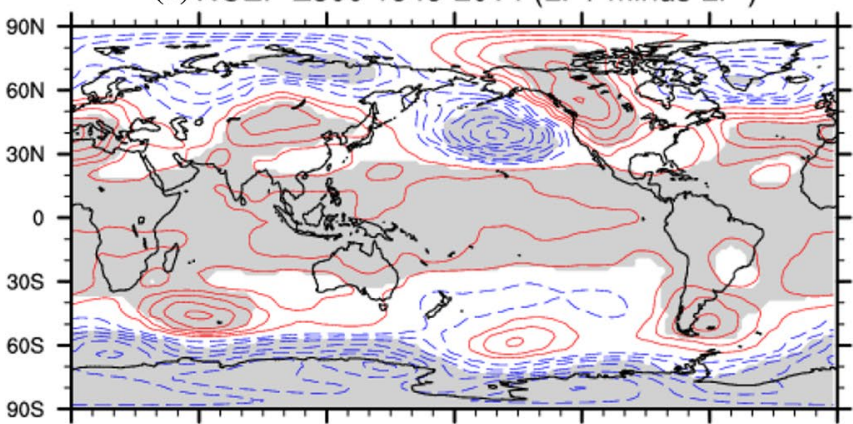

(d) NCEP Z500 1949-2014 (LF+ plus LF-)

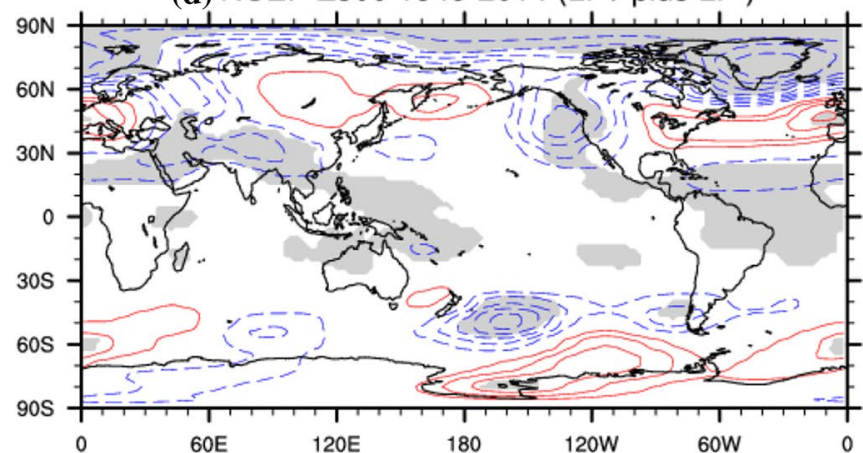

Fig. 3 Same as Fig. 2, but for DJFM Z500 anomalies (m). Sources are the NCEP/NCAR Reanalysis for 1949-2014 and the Twentieth Century Reanalysis for 1904-2014. Contour intervals are $10 \mathrm{~m}$. Neg-

have also been analyzed by Hoell et al. (2015) to examine impacts of Pacific decadal SST variability on Southwestern Asia climate changes. Because the GFDL runs are forced by the REOF2 forcing of Schubert et al. (2009), based on LF filtered data from July 1903 to June 2002, for consistency (e) 20th Z500 1904-2014 (LF+)

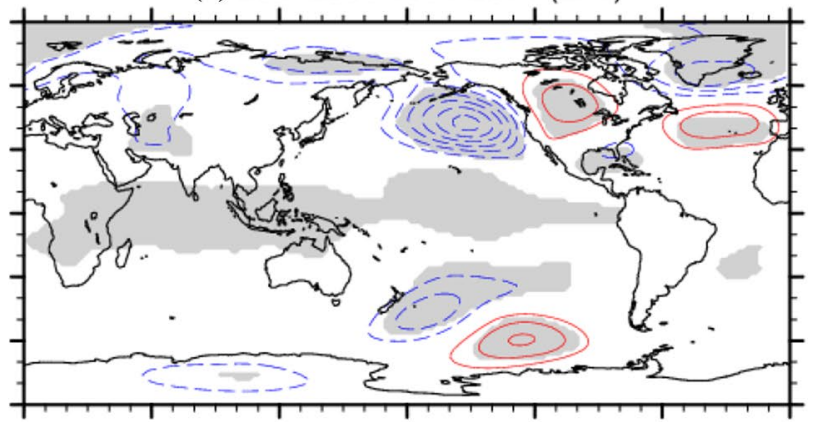

(f) 20th Z500 1904-2014 (LF-)

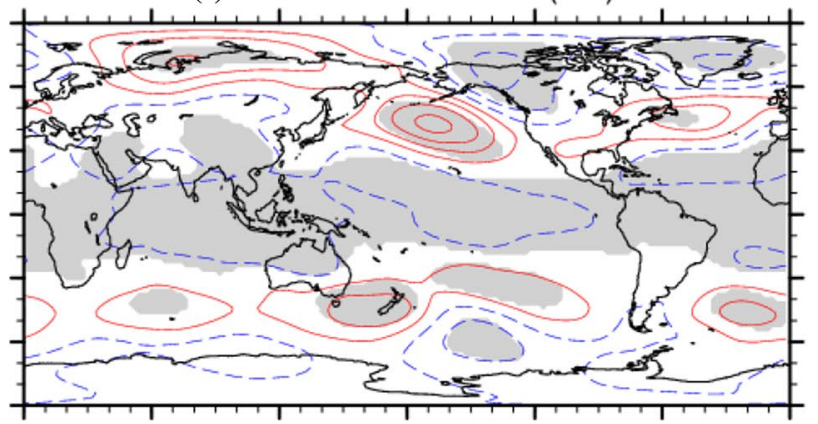

(g) 20th Z500 1904-2014 (LF+ minus LF-)

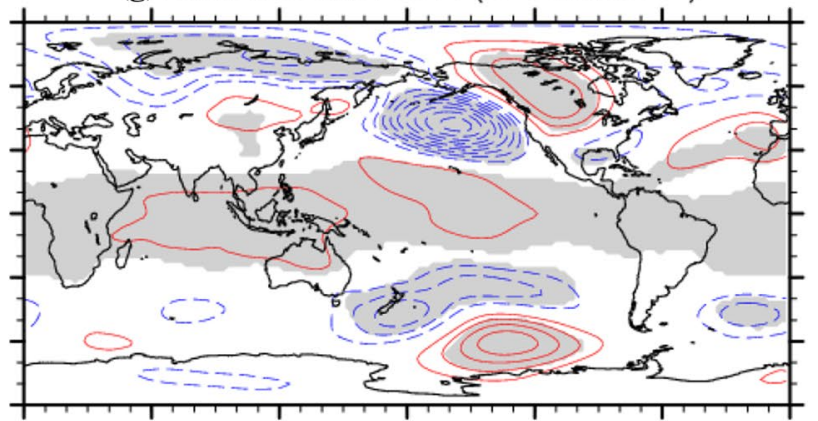

(h) 20th Z500 1904-2014 (LF+ plus LF-)

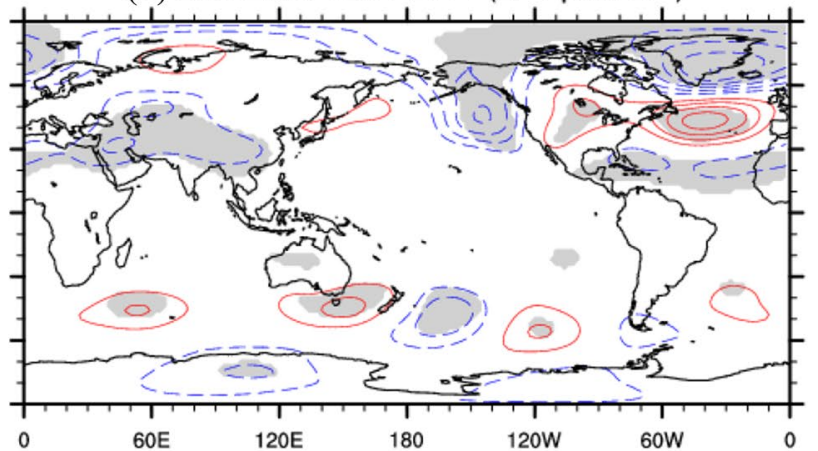

ative contours are dashed and the zero line is omitted. Shaded areas denote local statistical significance of values at the $95 \%$ confidence level

the CAM4 runs use the same forcing rather than an updated forcing based on REOF2 covering July 1903 to June 2014. Because REOF1 is the long-term SST trend pattern, the REOF2 pattern based on data ending June 2014 (not shown) is almost identical to the Schubert et al. (2009) REOF2 
(a) OBS Pr 1949-2014 (LF+)

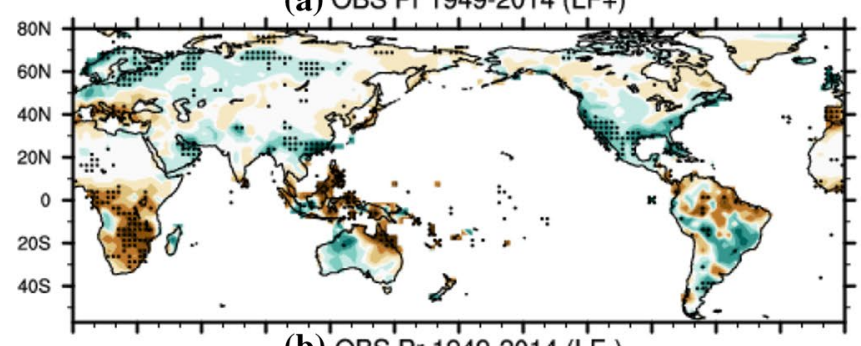

(b) OBS Pr 1949-2014 (LF-)

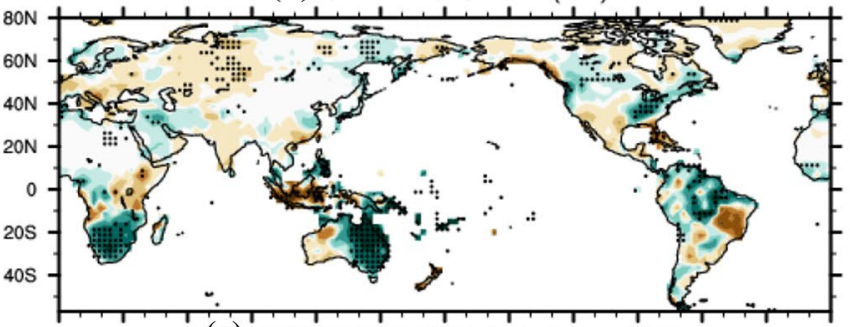

(c) OBS Pr 1949-2014 (LF+ minus LF-)

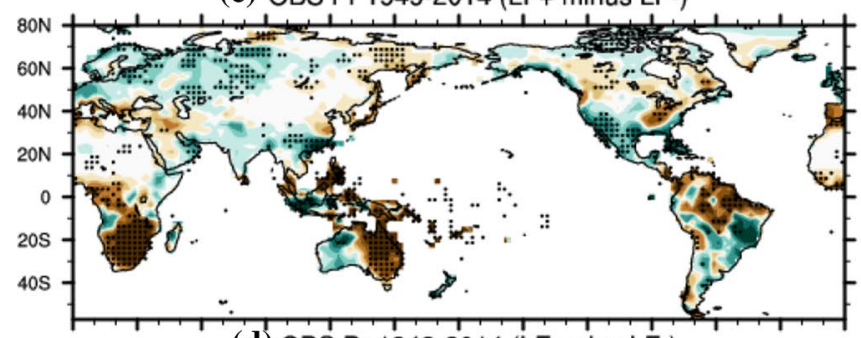

(d) OBS Pr 1949-2014 (LF+ plus LF-)

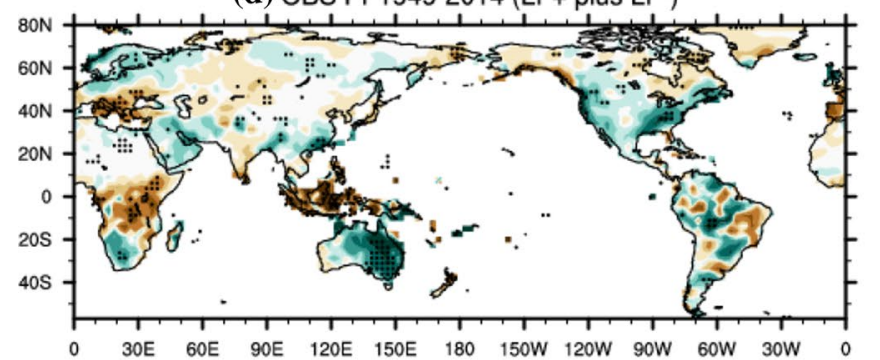

$-30 \quad-20$ (e) OBS Pr 1904-2014 (LF+)

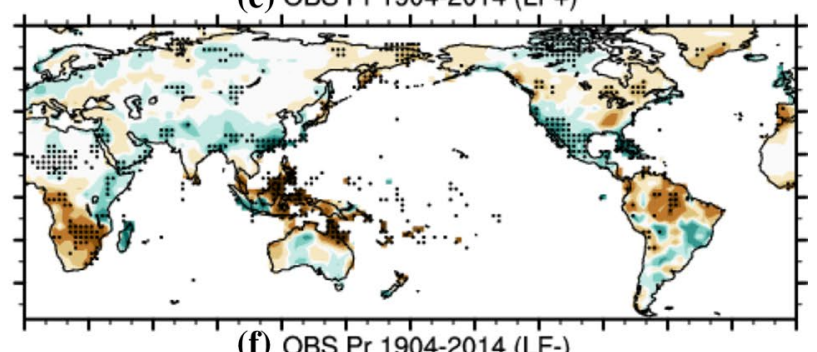

(f) OBS $\operatorname{Pr} 1904-2014$ (LF-)

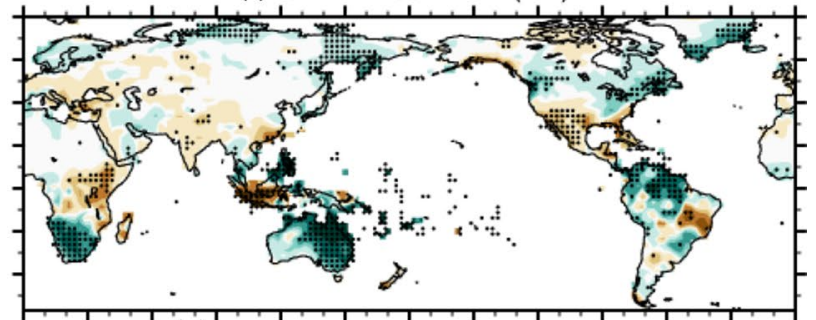

(g) OBS Pr 1904-2014 (LF+ minus LF-)

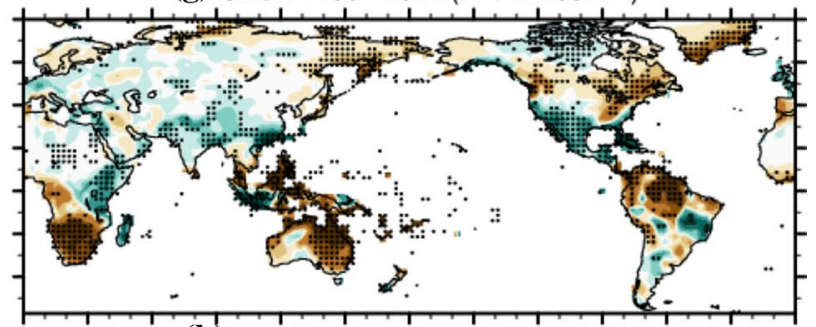

(h) OBS Pr 1904-2014 (LF+ plus LF-)

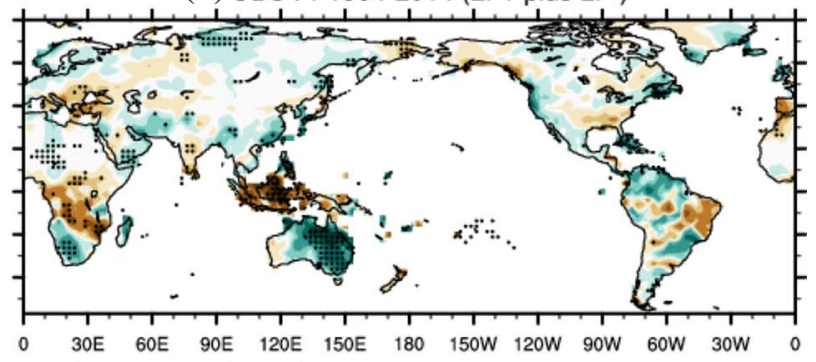

Fig. 4 Same as Fig. 2, but for DJFM land precipitation anomalies (mm/month). The source is the Global Precipitation Climatology Centre (GPCC) dataset

pattern. For a model, analyses of the composite strong positive $\mathrm{LF}+$ and strong negative $\mathrm{LF}-$ phase responses, linear or symmetric response (LF+ minus LF-), nonlinear or asymmetric response ( $\mathrm{LF}+$ plus $\mathrm{LF}-$ ), and statistical significance are performed in the same way as for observed data.

To focus on impacts of LF Tropical Pacific (LFTP) forcing, we also conduct experiments (see Sect. 4.2) with the CAM4 model where the LF SST anomalies are prescribed only in the Tropical Pacific region indicated by the rectangular box in Fig. 1a. The prescribed SST forcing patterns are the same as in the CAM4 strong LF+ and LF- runs described in Sect. 2, except that SST anomalies outside the rectangular box are kept at zero, with climatological SST from the CLM run and the same run durations (10-year spinup, then 200 years analyzed), so the corresponding runs are referred to as LFTP+ and LFTP-.

The physical link by which tropical SST forcing affects atmospheric circulation involves diabatic heating anomalies caused by marine rainfall changes (Trenberth and Hurrell 1994). Diagnostic studies also suggest that anomalous transients (synoptic-scale systems) play a more significant role than tropical heating in maintaining mid-latitude atmospheric circulation anomalies (e.g., Ting and Hoerling 1993). In addition to the tropical precipitation change, the effect of transients may also contribute to the nonlinear atmospheric response to tropical SST forcing, as suggested by DeWeaver and Nigam (2002). In this study, quantitative linear and nonlinear impacts of the transient eddy forcings on the mean 
Table 1 Spatial anomaly correlations (R columns) and RMS anomalies (RMS + and RMS - columns) of Z500 composite anomaly patterns in specified circumstances, averaged over the North Pacific-North America sector $\left(20^{\circ}-70^{\circ} \mathrm{N}, 150^{\circ} \mathrm{E}-60^{\circ} \mathrm{W}\right)$ or the North Atlantic-Europe sector $\left(20^{\circ}-90^{\circ} \mathrm{N}, 90^{\circ} \mathrm{W}-40^{\circ} \mathrm{E}\right)$

\begin{tabular}{|c|c|c|c|c|c|c|c|}
\hline & \multirow{2}{*}{$\begin{array}{l}\text { Period or model and } \\
\text { (LF type) }\end{array}$} & \multicolumn{3}{|c|}{ North Pacific-North America } & \multicolumn{3}{|c|}{ North Atlantic-Europe } \\
\hline & & $\mathrm{R}$ & RMS+ & RMS- & $\mathrm{R}$ & RMS+ & RMS- \\
\hline \multirow[t]{2}{*}{ OBS } & 1949-2014 LF & -0.46 & 17.3 & 20.2 & 0.45 & 28.6 & 16.3 \\
\hline & 1904-2014 LF & -0.63 & 19.3 & 13.8 & 0.64 & 15.4 & 10.6 \\
\hline \multirow[t]{6}{*}{ AGCM } & GFDL LF & -0.23 & 14.4 & 10.4 & 0.24 & 5.7 & 6.6 \\
\hline & CAM4 LF 200 yr & -0.96 & 15.4 & 8.9 & -0.81 & 5.7 & 5.5 \\
\hline & CAM4 LF $150 \mathrm{yr}$ & -0.95 & 15.4 & 9.3 & -0.69 & 5.8 & 6.0 \\
\hline & CAM4 LF 100 yr & -0.95 & 14.2 & 11.3 & -0.50 & 5.9 & 8.1 \\
\hline & CAM4 LF 50 yr & -0.92 & 17.9 & 16.0 & -0.45 & 9.7 & 10.0 \\
\hline & CAM4 LFTP & -0.92 & 14.5 & 12.4 & -0.36 & 4.3 & 8.7 \\
\hline
\end{tabular}

Circumstances are data rows: 1949-2014 NCEP reanalysis and 1904-2014 twentieth century reanalysis, GFDL 50-year model simulations, CAM4 200-year LF+and LF- model simulations averaged (4 data lines) for all 200 and for the first 150, 100 and 50 years, and (last data row, see Sect. 4.2) CAM4 200-year LFTP+ and LFTP- model simulations. Statistics are data columns: (R columns) Spatial anomaly correlations for the specified sector, named in top row, between the Z500 responses in positive versus negative phase composites. (RMS + columns) RMS Z500 differences (m) from climatology for observations or from climatological forcing for a model in the specified positive LF phase. (RMS - columns) Same as RMS + column except for specified negative LF phase

flow at the 300-hPa level are further calculated by the geopotential height tendency method outlined in Lau (1988, his Eqs. 1 and 2). Where $\pi$ is defined as convergence of the vorticity flux of transient eddies, the geopotential height tendency $\partial \mathrm{z} / \partial \mathrm{t}$ is proportional to the inverse Laplacian of $\pi$ :

$\frac{\partial z}{\partial t}=\frac{f}{g} \nabla^{-2} \pi$

$\pi \equiv \frac{1}{a^{2} \cos \theta}\left(\frac{\partial}{\partial \theta} \frac{1}{\cos \theta} \frac{\partial}{\partial \theta} \cos ^{2} \theta-\frac{1}{\cos \theta} \frac{\partial^{2}}{\partial \lambda^{2}}\right) \overline{u^{\prime} v^{\prime}}+\frac{1}{a^{2} \cos ^{2} \theta} \frac{\partial^{2}}{\partial \lambda \partial \theta} \cos \theta\left(\overline{u^{\prime 2}}-\overline{v^{\prime 2}}\right)$

where $a$ is the earth radius, $f$ is the Coriolis parameter, $g$ is the gravitational acceleration, $\lambda$ is the longitude, $\theta$ is the latitude, and $u$ and $v$ are zonal and meridional wind components associated with 2-8-day filtered fluctuations, respectively, the overbar is the time average, and primes denote deviations from the corresponding time mean quantities. Through a similar analysis, Abid et al. (2015) find that the transient eddy feedback to the PNA circulation anomalies is about $50 \%$ stronger during El Niño events than during La Niña, and this difference in the transients contributes significantly to the different atmospheric signals in the PNA region.

\section{Observational analysis}

For Z500, DJFM winters 1949-2014 are analyzed using the NCEP/NCAR Reanalysis, but DJFM winters 1904-2014 are separately analyzed using the Twentieth Century Reanalysis to increase the number of strong LF samples, and to show that similar major LF responses are seen in the longer data period. For SAT and precipitation, the NOAA SAT and GPCC precipitation datasets are used to cover 1949-2014 and 1904-2014. In Fig. 2, NOAA SAT anomalies over oceans are actually SST anomalies, and SST anomalies are plotted to better explain the complete spatial response of SAT and Z500.

We first discuss results in DJFM winters 1949-2014 due to the reliable historical data source for this period. The observed SAT LF+ response (Fig. 2a) shows significant surface warming over Russia and northern Europe, northern South America, and southern Africa, and significant cooling over the Sahara and South Asia. The LF-SAT response (Fig. 2b) is generally opposite to that for LF+ except for significant cooling over northwestern North America, much of northern Africa to South Asia, and Australia, and less extensive insignificant cooling over Eurasia. In Fig. 2c, the estimated linear SAT response shows widespread significant warming responses, and in Fig. 2d the nonlinear component shows significant cooling over the Sahara, South Asia, and northern South America, and significant warming over Scandinavia and the coastal eastern United States. The linear response over North America is similar to the regression pattern of SAT on the PDO index in Mantua et al. (1997). The linear components in Fig. 2c, g show SST patterns throughout the Pacific and Indian Ocean nearly identical to the REOF2 pattern in Fig. 1a. In Fig. 2a, b, because most ocean SST changes show weaker warming or stronger cooling with $\mathrm{LF}+$ than the corresponding opposite responses 
in LF-, Fig. 2d shows widespread and mostly significant nonlinear cooling SST responses, possibly explaining why Fig. $2 d$ also shows significant nonlinear cooling SAT responses over most land areas.

In Fig. 3a, b, observed LF+ and LF- Z500 response composites have similar magnitudes over the North Pacific, but anomalies over North America are much stronger with LF- while anomalies over the North Atlantic and European regions are much stronger with $\mathrm{LF}+$. The longitude shift with El Niño versus La Niña in mid-latitudes (Hoerling et al. 1997, 2001; Zhang et al. 2014) is also found here. The North Pacific (North America) LF- anomaly center is about $15^{\circ}$ $\left(30^{\circ}\right)$ west of the corresponding $\mathrm{LF}+$ center. Figure $3 \mathrm{a}, \mathrm{b}$ also show a significant NAO-like response to $\mathrm{LF}+$, but a barely significant NAO response to LF- with no significant positive North Atlantic or European Z500 response. In Fig. 3c, significant $\mathrm{NH}$ extratropical linear components of Z500 anomalies include the well-known PNA teleconnection pattern (Wallace and Gutzler 1981; Mantua et al. 1997) and a positive NAO-like pattern (Wallace and Gutzler 1981), and the Southern Annular pattern is seen in the SH (Thompson and Wallace 1998). An additional significant linear response is a dipole over Eurasia including a positive Z500 anomaly centered near Lake Baikal and a negative Z500 anomaly over high latitudes and the adjacent Arctic Ocean, which is similar to composite Z500 anomaly patterns associated with strong IPO phases found by Dong and Dai (2015), and explains the large warming linear response over northern Eurasia in Fig. 2c. In Fig. 3c, Z500 has positive linear responses everywhere in the tropics, reflecting general lower tropospheric warming forced by the underlying LF+tropical SST warming in Fig. 1a. In Fig. 3d, major $\mathrm{NH}$ extratropical nonlinear Z500 anomalies include a strong PNA-like response with a large negative/positive anomaly dipole with centers over coastal western and eastern North America, and a significant positive NAO-like pattern in the North Atlantic (mainly due to the significant LF+and nearly insignificant LF- NAO responses).

The right columns of Figs. 2 and 3 show analyses of 1904-2014 NOAA SAT and Z500 from the Twentieth Century Reanalysis that were performed to increase the number of strong LF samples, totaling $49 \mathrm{LF}+$ and $57 \mathrm{LF}-$ months out of 440. In Fig. 2e, f, the observed LF+ and LF- SAT responses in 1904-2014 are in general similar to the corresponding SAT responses in 1949-2014, but show mostly smaller significant areas especially over land. Note that significant negative SAT responses over northern Eurasia are associated with LF- in both periods, while large areas with significant warming SAT responses over northern Eurasia are found with LF+ only in 1949-2014. In Fig. 2g, the estimated linear component of the SAT response shows significant warming responses over northwestern North America, central Eurasia, South Africa, northern South America and eastern Australia, and significant land cooling over relatively small parts of eastern North America and the Middle East. In Fig. 2h, the nonlinear component shows little significant cooling over land except from South Asia to the Sahara, and less significant cooling SST through the Pacific and Indian Oceans. The main features of linear $\mathrm{Z} 500$ responses seen in 1949-2014 are also robust in observations covering over 111 years, including several PNA-like responses, a significant dipole linear response over Eurasia in Fig. 3c, g, and several significant nonlinear PNA and NAO-like responses to the LF forcing (Fig. 3d, h). However, a weak linear NAO response to LF forcing and a significant nonlinear NAO response to LF forcing is found in Fig. $3 \mathrm{~g}$, h mainly due to nearly equal NAO responses to both $\mathrm{LF}+$ and $\mathrm{LF}-$ forcing.

The first two data rows of Table 1 quantify the nonlinearity of observed Z500 anomalies in opposite strong observed LF phases by showing the average correlation (R) of anomalies between positive and negative phases, and the root-mean-square differences (RMS, units are m) separately for LF+ and LF- phases, averaged over the North PacificNorth America $\left(20^{\circ}-70^{\circ} \mathrm{N}, 150^{\circ} \mathrm{E}-60^{\circ} \mathrm{W}\right)$ and North Atlantic-Europe $\left(20^{\circ}-90^{\circ} \mathrm{N}, 90^{\circ} \mathrm{W}-40^{\circ} \mathrm{E}\right)$ sectors. In the North Pacific-North America sector, strong LF composites show substantial linearity (negative correlations) in PNA-like responses, with correlations -0.46 between $\mathrm{LF}+$ and $\mathrm{LF}-$ in 1949-2014 and - 0.63 in 1904-2014. The RMS anomaly amplitude is slightly larger for $\mathrm{LF}-$ than for $\mathrm{LF}+(20.2$ versus $17.3 \mathrm{~m}$ ) in 1949-2014, but is much larger for LF+ than in LF- (19.3 versus $13.8 \mathrm{~m}$ ) during 1904-2014. In the North Atlantic-Europe sector, strong LF composites show substantial nonlinearity (positive correlations) in NAO-like responses (Fig. 3a, b, e, f), with correlations 0.40 between LF+ and LF- in 1949-2014 and 0.64 in 1904-2014. In both periods, the RMS anomalies are larger for LF+than for LF- (28.6 versus 16.3 in 1949-2014, and 15.4 versus $10.6 \mathrm{~m}$ in 1904-2014).

In Fig. 4, DJFM precipitation in both 1949-2014 and 1904-2014 generally responds nearly linearly to strong LF phases except for a strong positive nonlinear response over eastern Australia, as shown by mostly small nonlinear responses in Fig. 4d, h. Figure 4a, b, e, f show that the southwestern USA is wet with LF+ and dry with LF-, consistent with the composite analysis of Dai (2013), and precipitation anomalies in the northeastern and northwestern USA are almost opposite. However, these southwestern USA precipitation responses are significant with $\mathrm{LF}+$ forcing in both periods, but only significant to LF- forcing in 1904-2014. In both periods, significant positive (negative) precipitation responses to LF+ are found over western Russia, and eastern and northwest China (southern Africa), while significant large-scale positive (negative) precipitation responses to LF- are found over southern South Africa, northern South America and eastern Australia (western Russia). In 
both periods (Fig. 4c, g), overall significant linear precipitation responses to strong LF events are increases over the southwestern USA, and eastern and northwestern China, and decreases over South Africa, eastern Australia, northern South America and eastern Siberia. In Fig. 4c (1949-2014), significant positive linear precipitation responses are found over northern Europe and western Russia, and in Fig. 4g (1904-2014) over the Middle East and South Asia, while in the same panel, significant negative linear precipitation responses are found over eastern North America, and the northwestern United States.

Overall, Figs. 2, 3 and 4 indicate that most linear and nonlinear responses of all three atmospheric variables to strong LF forcing are robust over the North Pacific-North America region and Eurasia in both 1949-2014 and 1904-2014, while some linear and nonlinear responses over the North Atlantic-European sector are affected by the limited number of observed strong LF+ and LF- months. As mentioned in Sect. 2, analyses were also performed (not shown) based on a recomputed REOF2 pattern and PC2 time series covering July 1903 to June 2014, instead of the above analyses with the PC2 time series through June 2014 computed based on the Schubert et al. (2009) REOF2 covering July 1903-June 2002. Responses were quite similar because, due to the small change in the REOF2 pattern, almost all of the same months were composited as strong LF+ and LF- months. In the next section, we examine which linear and nonlinear features are reproducible in numerical simulations with continuous strong LF forcing.

\section{Simulation analysis}

\subsection{Atmospheric responses to the LF forcing}

Figures 5, 6 and 7 present responses of atmospheric fields of SAT, Z500 and precipitation to strong LF forcing simulations in CAM4 and GFDL. In Fig. 5a, b, e, f, responses of SAT to both $\mathrm{LF}+$ and $\mathrm{LF}-$ forcing are quite similar in each model, except over certain regions of Eurasia where the models simulate opposite responses. The response patterns to LF+ and LF- simulations are approximately opposite for both AGCMs (especially for CAM4) because the $\mathrm{LF}+$ and LF- forcings are symmetric. In Fig. $5 \mathrm{~d}$, h, both models simulate robust asymmetries in nonlinear responses over western North America because in the top two rows of Fig. 5, the warm responses to LF+ SST forcing are strong and significant in that region, but with LF- forcing corresponding cold anomalies are somewhat weaker and less significant. In Fig. 5h, nonlinearity is strong over Eurasia in GFDL since both LF+ and LF- simulate a similar response, with cold anomalies over eastern Russia and warm anomalies over other areas of Eurasia. There are considerable discrepancies of responses between observations (Fig. 2a-d) and the two models, partially possibly due to the small number of observed LF+ and LF- cases. In Fig. 5c, g, although the predominant observed (Fig. 2c) significant linear warming SAT response over North America and most southern land areas with strong LF forcing is generally reproduced in the simulations of both AGCMs, significant observed linear warming responses over central Eurasia are not reproduced in either AGCM since neither model simulates significant $\mathrm{LF}+$ warming or $\mathrm{LF}-$ cooling.

In Fig. 6a, b, e, f, both models simulate reasonably similar PNA-like patterns of the Z500 response to LF+ or LF- forcing although the simulation length (50 year) is much shorter in GFDL than in CAM4 (200 year). Over the North Pacific and North America, both models simulate about twice the Z500 response magnitude with $\mathrm{LF}+$ forcing as with $\mathrm{LF}-$, with some spatial differences. With $\mathrm{LF}+$, the minimum Aleutian Low anomaly is about -35 to $-40 \mathrm{~m}$ in both models, while with LF- the maximum Aleutian High pressure anomaly is $15-25 \mathrm{~m}$. The response to $\mathrm{LF}+$ forcing in North America has a maximum value of $25 \mathrm{~m}$, centered in both models over western Canada, while the LF- negative response reaches a minimum of $-15 \mathrm{~m}$ centered over western Canada in CAM4 and over Alaska in GFDL. Therefore, in Fig. 6d, h, both models simulate a significant PNA-like nonlinear response although GFDL simulates a stronger negative anomaly over the Bering Sea, Alaska and eastern Siberia (possibly because of the short GFDL simulation length of 50 year). This indicates that the observed nonlinear PNA pattern (Fig. 2d, h) is a real atmospheric response to $\mathrm{LF}+$ and $\mathrm{LF}-$ forcing.

In the North Atlantic-Europe sector, the simulated Z500 responses to $\mathrm{LF}+$ and $\mathrm{LF}-$ forcing in both models (Fig. 6a, b, e, f) are either NAO-like but insignificant, or have little resemblance to NAO. A significant linear negative NAO response to LF SST forcing is found in CAM4, and a barely significant NAO-like nonlinear response is simulated in GFDL, but not in CAM4. However, observations (Fig. 3a, $\mathrm{d}, \mathrm{e}, \mathrm{f})$ show robust significant NAO responses to $\mathrm{LF}+$ forcing and nonlinear NAO responses to LF forcing in both the 1949-2014 and 1904-2014 periods. Therefore, there are considerable inconsistencies in atmospheric responses over the North Atlantic-European sector to LF SST forcings among observations and the two models.

To quantify aspects of model responses to LF+ and LF- forcing, the third and fourth data rows of Table 1 show spatial correlations of Z500 anomalies between LF+ and LF- in the North Pacific-North America sector (or PNA region) of -0.96 for CAM4, but only -0.23 for GFDL. The -0.96 correlation for CAM4 reflects strong symmetry of response patterns except for eastward shifts of North America anomaly centers for LF- compared to LF+, and the -0.23 correlation for GFDL reflects widespread differences 


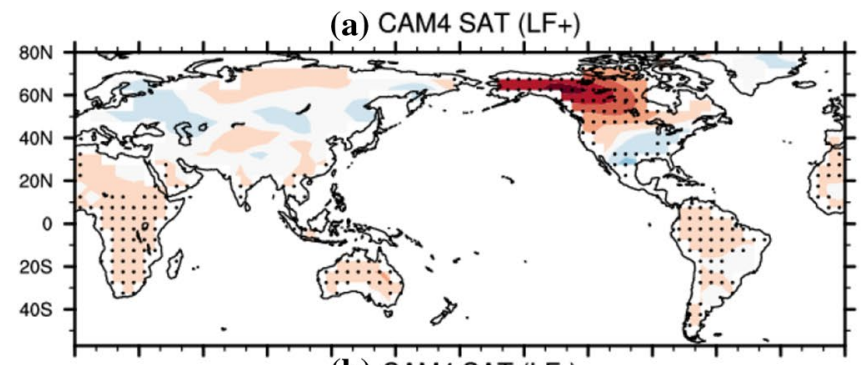

(b) CAM4 SAT (LF-)

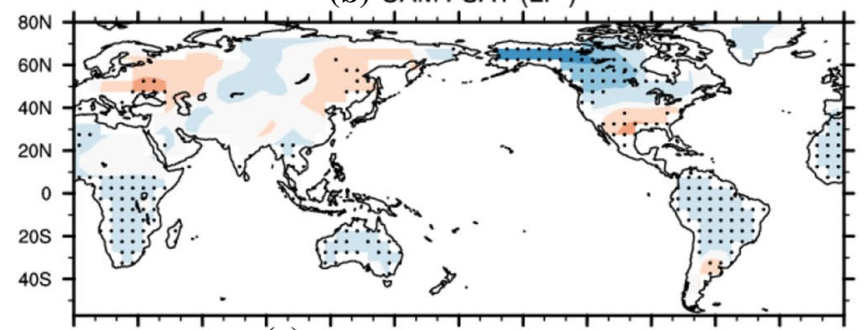

(c) CAM4 SAT (LF+ minus LF-)

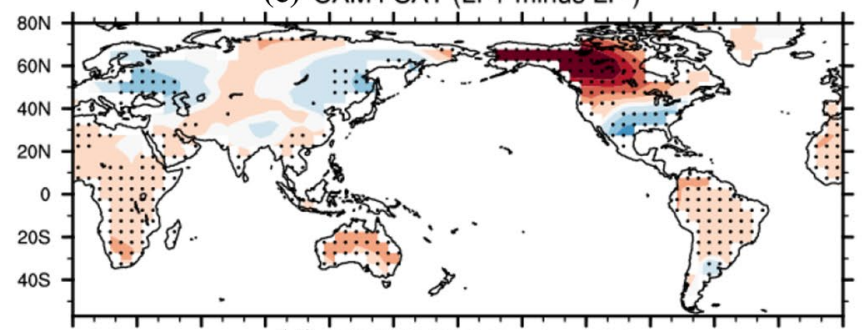

(d) CAM4 SAT (LF+ plus LF-)

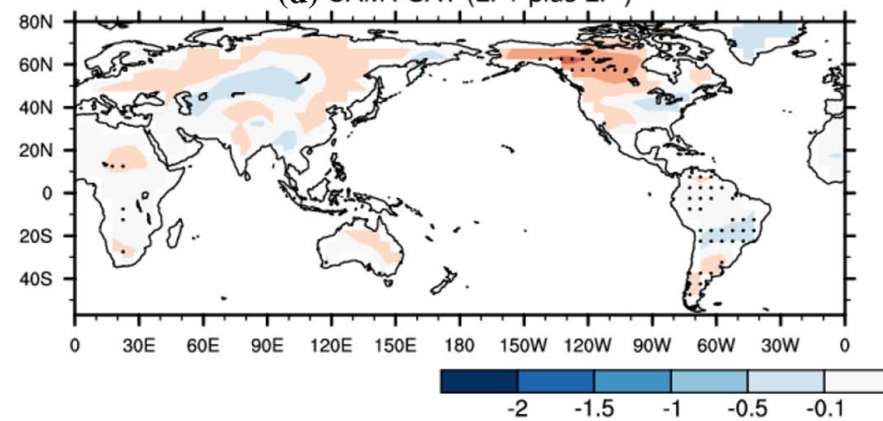

Fig. 5 Responses of SAT anomalies (K) to the (a, e) strong warm $(\mathrm{LF}+)$ and $(\mathbf{b}, \mathbf{f})$ cold $(\mathrm{LF}-)$ IPO/PDO-like low frequency Pacific SST anomalies simulated in CAM4 (left column) and GFDL_AM2.1 (right column). c, $\mathbf{g}$ Linear component of the SAT anomalies as esti-

between LF+ and LF- patterns. The RMS anomaly values for both models are larger with LF+ than with LF- over the PNA region. In the North Atlantic-Europe sector, spatial correlations of $\mathrm{Z} 500$ anomalies between $\mathrm{LF}+$ and $\mathrm{LF}-$ are -0.81 for CAM4, but +0.24 for GFDL, with similar RMS anomaly values for $\mathrm{LF}+$ and $\mathrm{LF}-$ in both models.

In Fig. 7a, b, e, f, the simulated DJFM land precipitation responses are similar to the observed responses (Fig. 4a, b, e, f), but only limited land areas reach statistical significance. Over southern North America, both models simulate significant wet LF+ and dry LF- responses. The DJFM precipitation response to $\mathrm{LF}+$ or $\mathrm{LF}-$ forcing is quite similar in both (e) GFDL SAT (LF+)

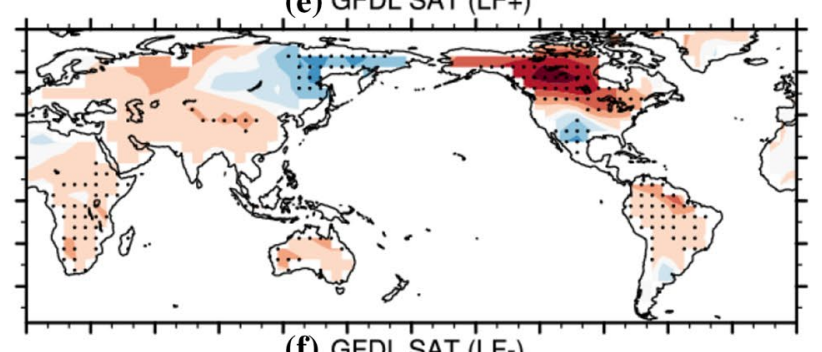

(f) GFDL SAT (LF-)

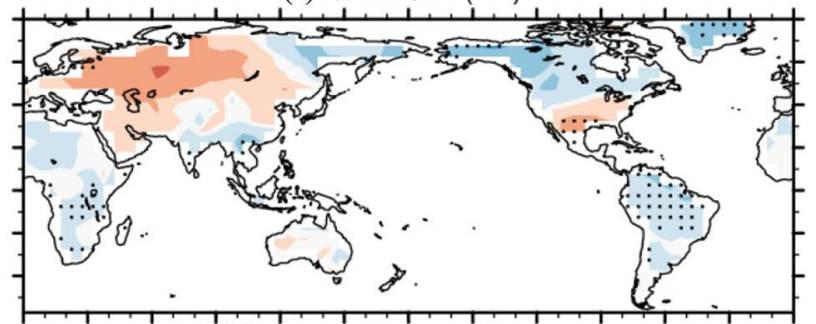

(g) GFDL SAT (LF+ minus LF-)

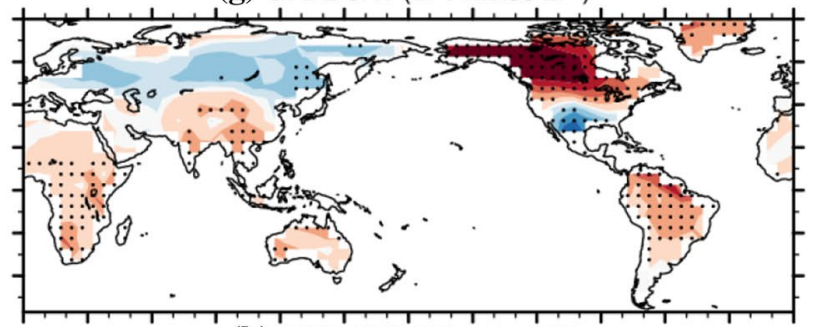

(h) GFDL SAT (LF+ plus LF-)

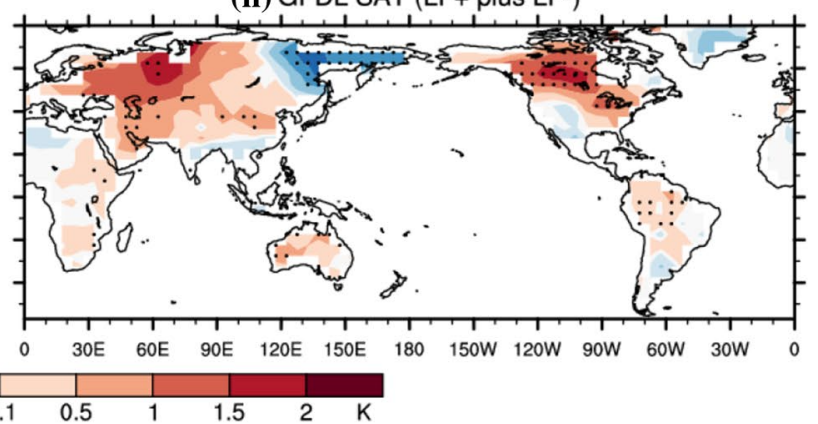

mated by the difference (a) minus (b) or (e) minus (f). d, h Nonlinear component of the SAT anomalies, as estimated by the sum (a) plus (b), or (e) plus (f). The black dots denote local statistical significance of values at the $95 \%$ confidence level models, but with LF- forcing the responses are opposite between models over Australia. In Fig. 7c, g, both models generally reproduce observed (Fig. 4c, g) significant linear increasing responses over southern North America, and linear decreasing responses over South Africa, Australia and northern South America. As in observations, simulated precipitation (Fig. 7c, d, g, h) appears to respond more linearly to strong LF forcing than temperature and Z500 (corresponding panels of Figs. 5, 6).

Figure 7 also shows the modeled DJFM marine precipitation responses to LF+ and LF- SST forcing. The strongest $\mathrm{LF}+$ response is a dipole-like pattern with rainfall increases 
(a) CAM4 Z500 (LF+)

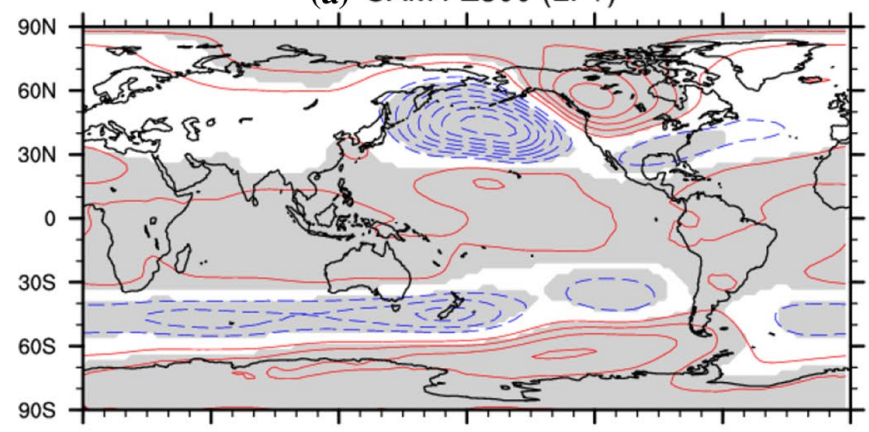

(b) CAM4 Z500 (LF-)

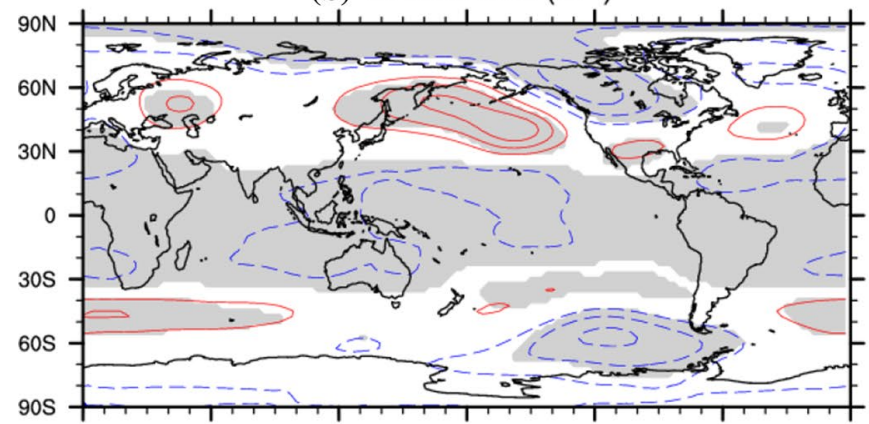

(c) CAM4 Z500 (LF+ minus LF-)

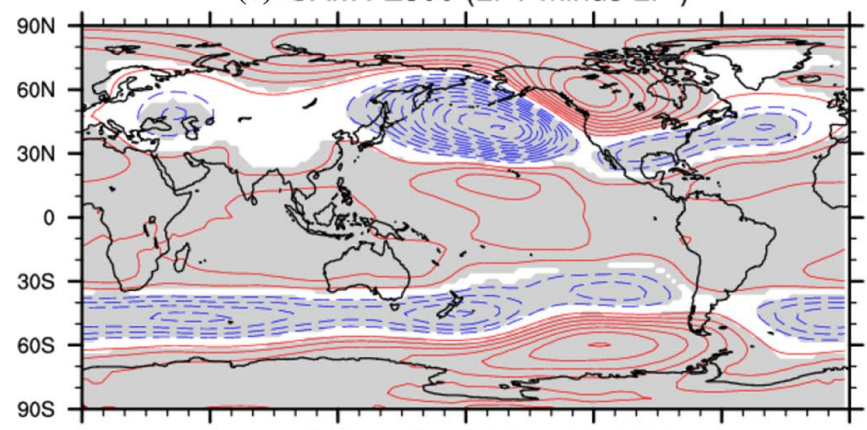

(d) CAM4 Z500 (LF+ plus LF-)

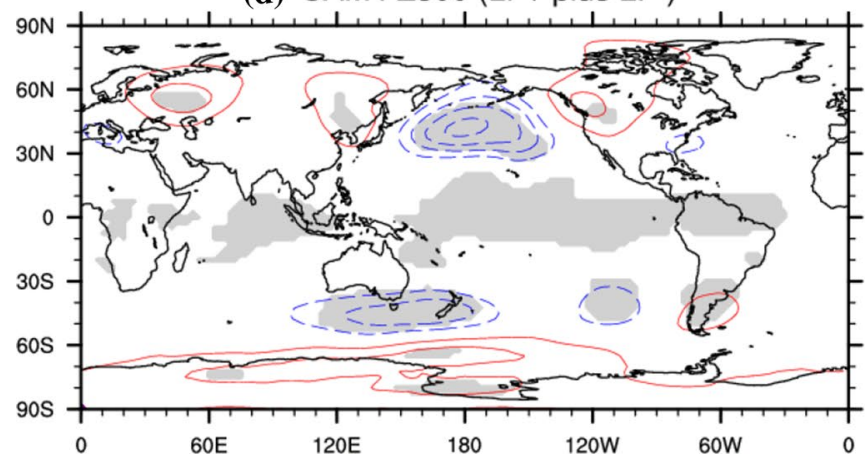

(e) GFDL Z500 (LF+)

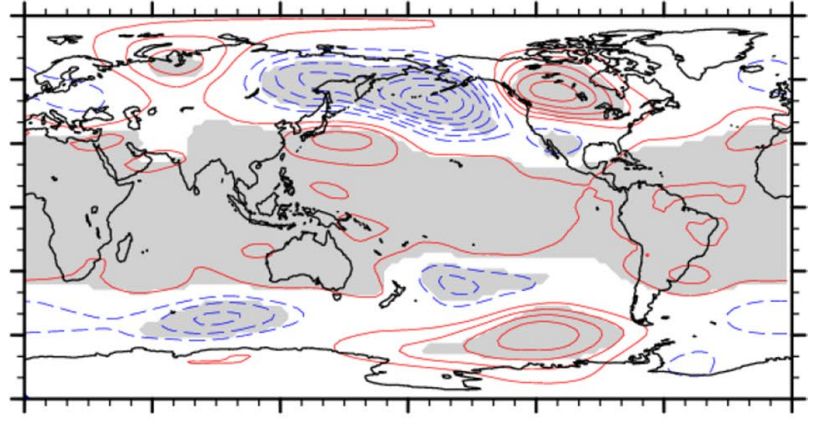

(f) GFDL Z500 (LF-)

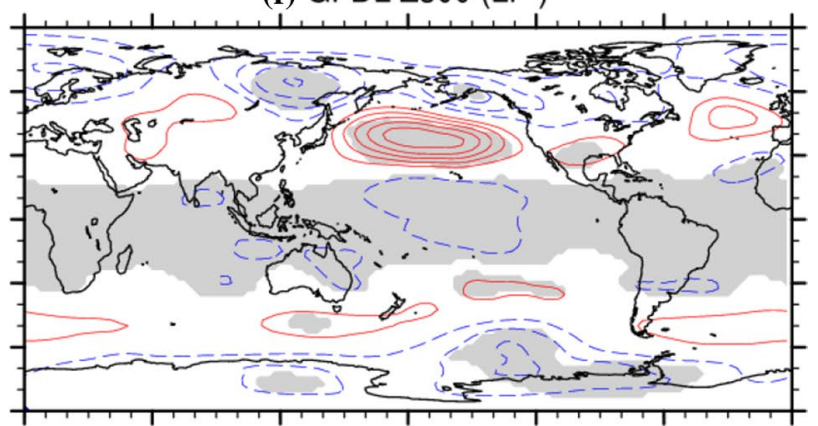

(g) GFDL Z500 (LF+ minus LF-)

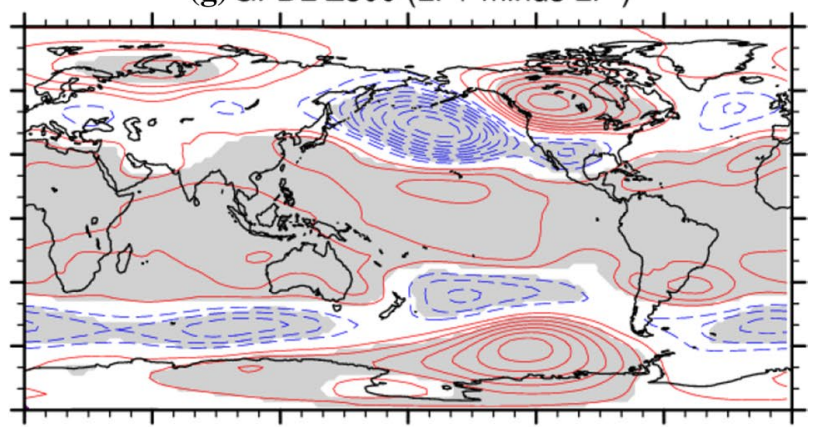

(h) GFDL Z500 (LF+ plus LF-)

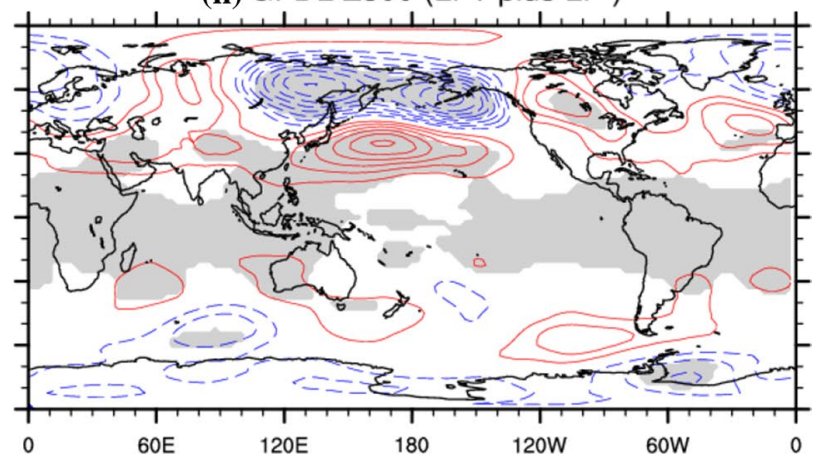

Fig. 6 Same as Fig. 5, but for DJFM Z500 anomalies. Contour intervals are $5 \mathrm{~m}$. Negative contours are dashed and the zero line is omitted. Shaded areas denote local statistical significance of values at the $95 \%$ confidence level

from east of Indonesia to South America mainly along $10^{\circ} \mathrm{N}$ and $10^{\circ} \mathrm{S}$ (a double ITCZ) and from east of Indonesia southeastward to near Easter Island, and rainfall decreases from southern India to east of northern New Zealand (the last two anomalies indicate an eastward shift of the South Pacific
Convergence Zone, SPCZ). In the tropics $\left(20^{\circ} \mathrm{S}-20^{\circ} \mathrm{N}\right.$, $0-360^{\circ} \mathrm{E}$ ), spatial correlation coefficients between $\mathrm{LF}+$ and LF- anomalies are -0.83 in CAM4 and -0.72 in GFDL, indicating a similar dipole pattern with relatively small nonlinear precipitation responses in Fig. 7d, h. The main 
(a) CAM4 PRECIP $\left(\mathrm{LF}_{+}\right)$

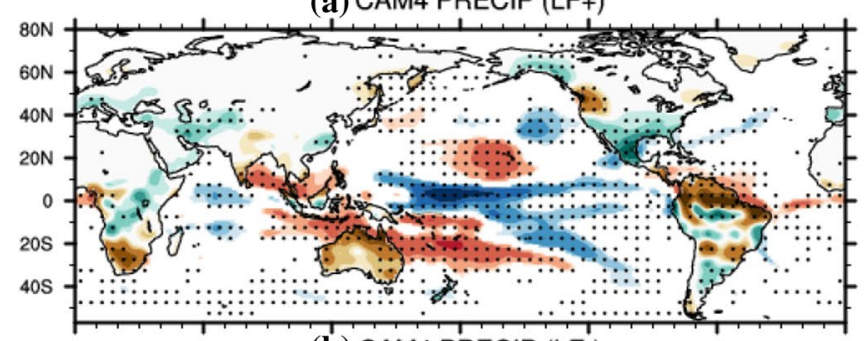

(b) CAM4 PRECIP (LF-)

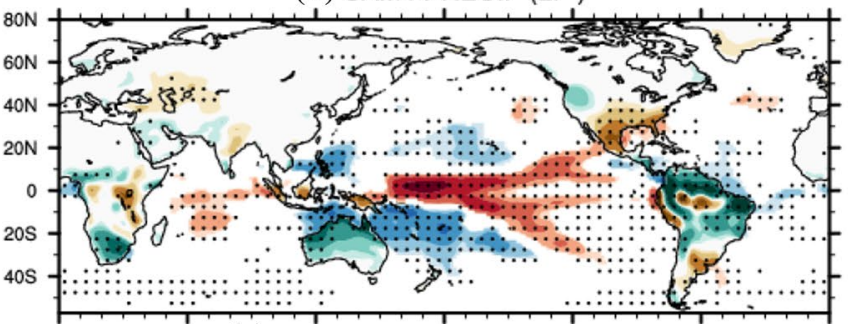

(c) CAM4 PRECIP (LF+ minus LF-)

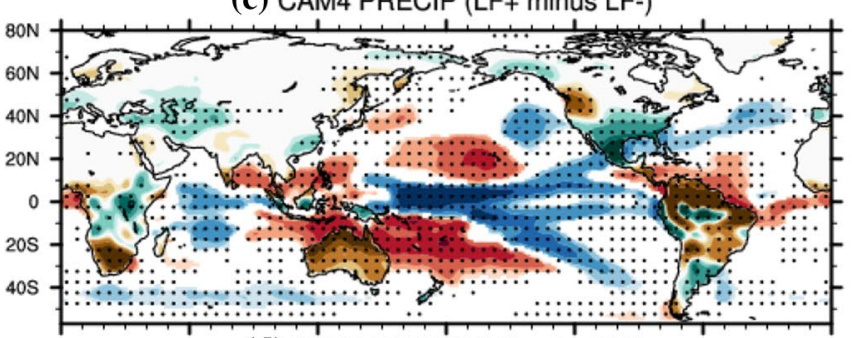

(d) CAM4 PRECIP (LF+ plus LF-)

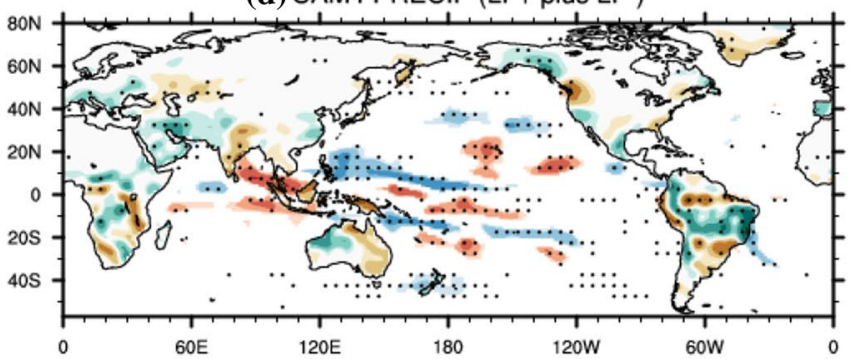

(e) GFDL PRECIP (LF+)

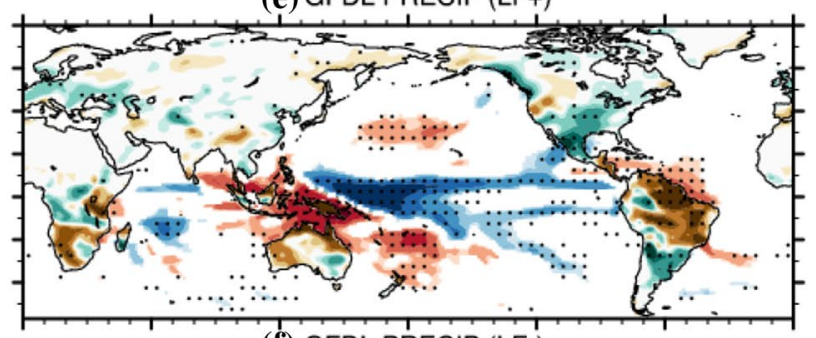

(f) GFDL PRECIP (LF-)

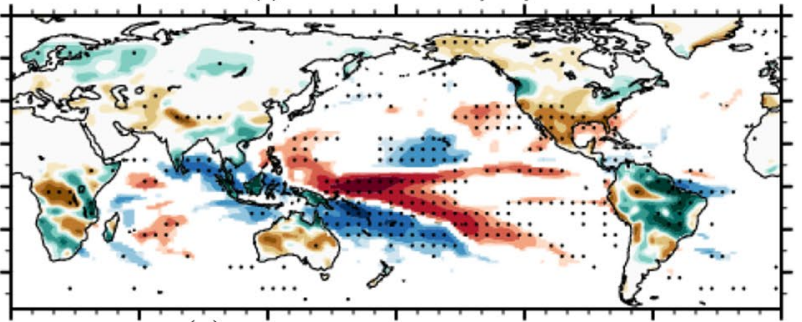

(g) GFDL PRECIP (LF+ minus LF-)

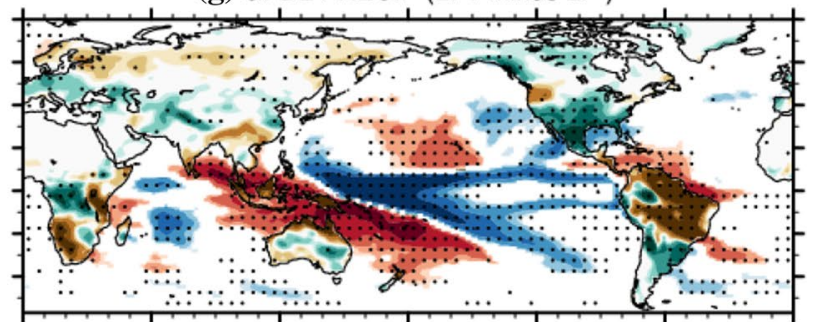

(h) GFDL PRECIP (LF+ plus LF-)

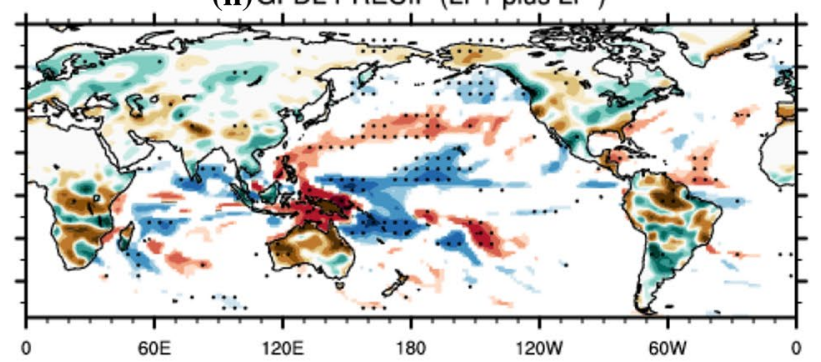

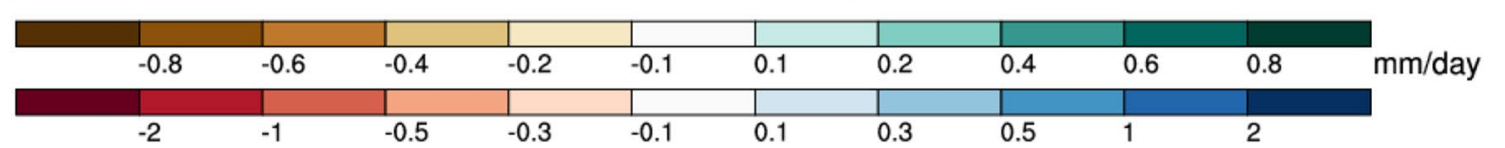

Fig. 7 Same as Fig. 5, but for DJFM precipitation anomalies ( $\mathrm{mm} /$ day). Note that green or blue shading indicates a wet anomaly, and the ocean color bar has larger anomaly intervals than the land color bar

nonlinearity of tropical rainfall reflects a stronger rainfall response to $\mathrm{LF}+$ than $\mathrm{LF}$ - forcing over the tropical western Pacific in CAM4 and the central Pacific around the date line in GFDL. The modeled tropical rainfall responses to the prescribed LF+ and LF- SST forcing support the hypothesis (Trenberth and Hurrell 1994) that diabatic heating caused by induced tropical rainfall changes is the physical link to the extratropical circulation responses, such as remote PNA-like and NAO-like responses. A difference between the LF (interdecadal) mode and ENSO is that neither model simulates the longitudinal precipitation shift between the eastern or central equatorial Pacific with El Niño and the Maritime Continent in La Niña (Hoerling et al. 1997, 2001).

Figure 8 shows DJFM ensemble averaged changes in eddy kinetic energy (EKE), or storm track changes in CAM4 (A similar analysis is not possible for GFDL because only monthly mean fields are available). EKE is defined as deviations of the 300-hPa horizontal wind speed $\left(u^{\prime 2}+v^{\prime 2}\right) / 2$ associated with 2-8 day filtered fluctuations, where $u$ and $v$ are zonal and meridional wind components, respectively, the overbar is the time average, and primes denote deviations from the corresponding time mean quantities. In Fig. 8a, LF+ shifts the mid-latitude storm track 
(a) CAM4 EKE (LF+)

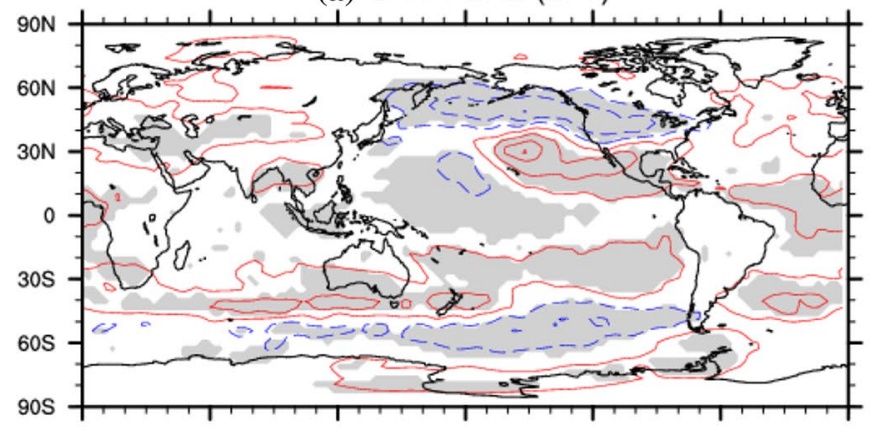

(b) CAM4 EKE (LF-)

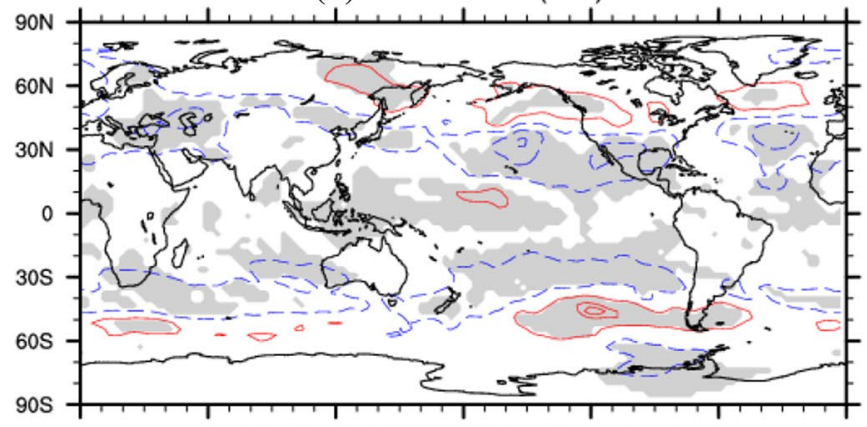

(c) CAM4 EKE (LF+ minus LF-)

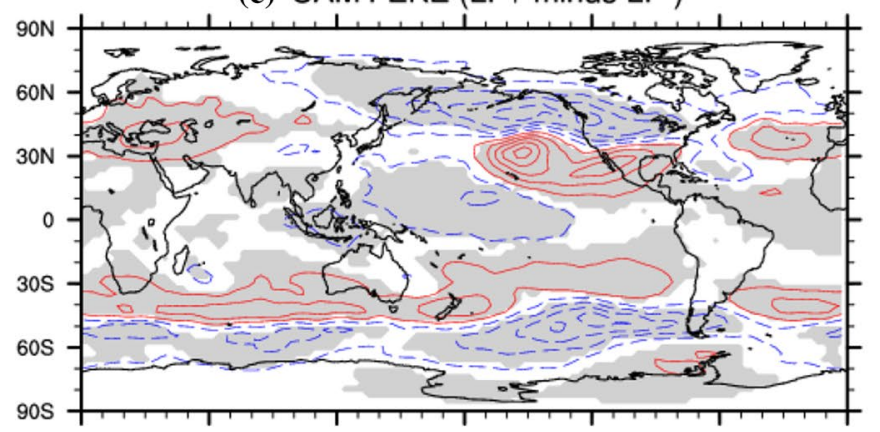

(d) CAM4 EKE (LF+ plus LF-)

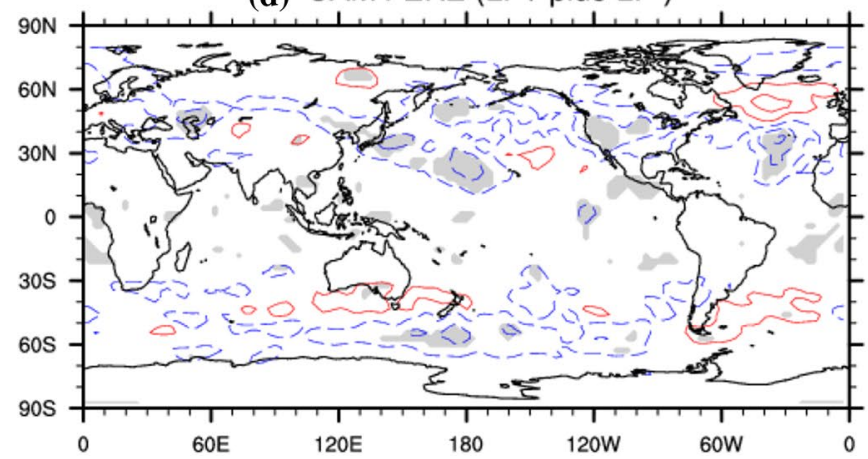

(e) CAM4 Z300 Tendencies (LF+)

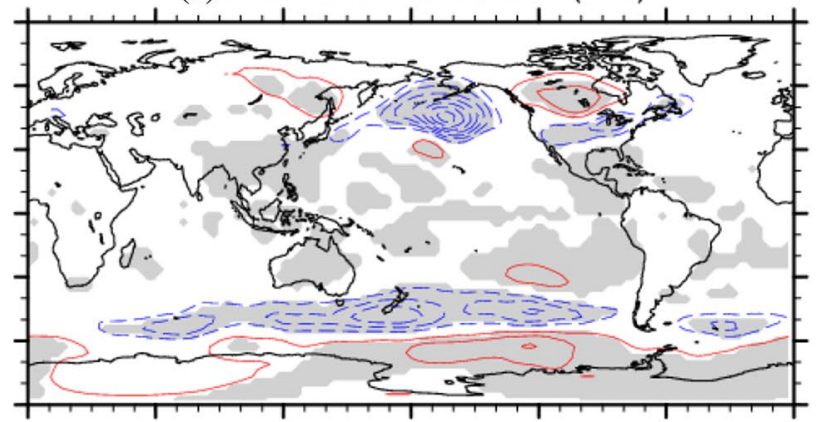

(f) CAM4 Z300 Tendencies (LF-)

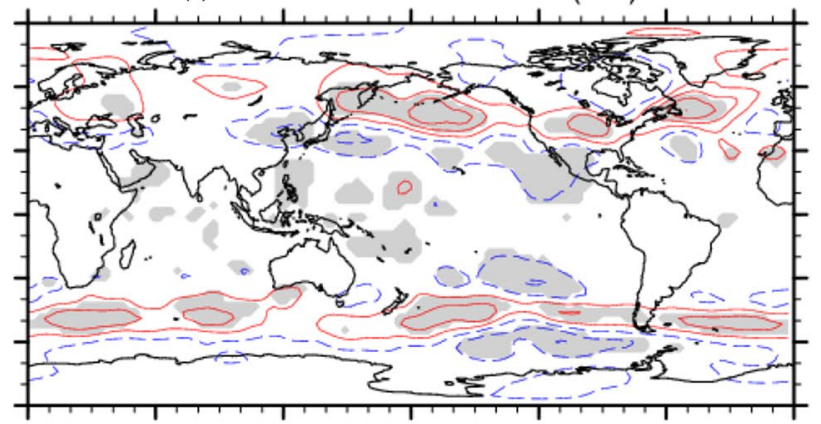

(g) CAM4 Z300 Tendencies (LF+ minus LF-)

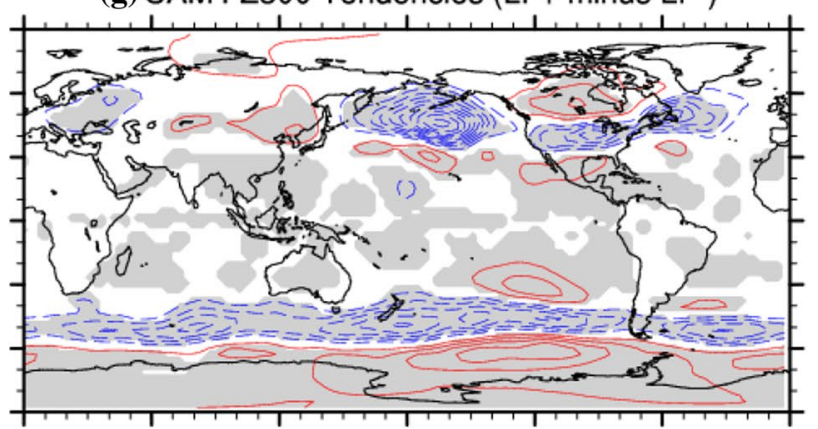

(h) CAM4 Z300 Tendencies (LF+ plus LF-)

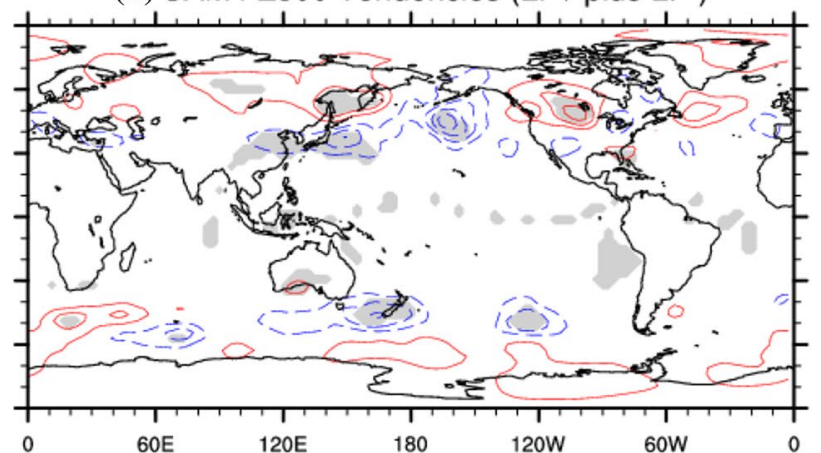

Fig. 8 Same as Fig. 5, but for DJFM eddy kinetic energy (EKE, $\mathrm{m}^{2} \mathrm{~s}^{-2}$, contour interval $1 \mathrm{~m}^{2} \mathrm{~s}^{-2}$ ) (left column), and $300 \mathrm{hPa}$ height tendencies $\left(\mathrm{m} \mathrm{s}^{-1}\right.$, contour interval $\left.0.5 \times 1 \mathrm{e}^{-5} \mathrm{~ms}^{-1}\right)$ (right column) in CAM4

south over the North Pacific and North America, while LF- shifts the mid-latitude storm track poleward in both hemispheres. The linear responses (Fig. 8c) include a significant dipole-like structure over the central and eastern parts of the North Pacific, significant increases over the subtropical North Atlantic and western Eurasia, and significant increases around $40^{\circ} \mathrm{S}$ with decreases around $60^{\circ} \mathrm{S}$ (an equatorward shift of the SH extratropical storm track). In Fig. 8d, nonlinear EKE responses include nearly 
continuous mid-latitude belts of fairly large but less significant negative nonlinear responses in both hemispheres.

Figure 8e, f show that transient eddies in both strong $\mathrm{LF}+$ and LF- periods induce significant decreasing $300 \mathrm{hPa}$ height tendencies in the extratropics in both hemispheres, which coincide well with the corresponding strong positive or negative Z500 anomaly centers in Fig. 6a, b. Similarly, most major height tendency centers showing linear and nonlinear responses to strong LF forcing in Fig. 8g, h coincide approximately with Z500 anomaly centers of the same sign in Fig. 6c, d. In general, the growth and maintenance of the linear and nonlinear PNA-like circulation responses and the negative NAO-like linear response in winter to strong LF forcing involve feedback by synoptic transient eddies.

To estimate the length of a model simulation required to identify robust LF+ and LF- responses (with the implication that a similar period of observations may also be required to verify robustness), we compare the Z500 responses to strong LF forcing in CAM4 for the first 50, 100, and 150 years of simulation with the full 200 year simulation. The left column of Fig. 6 (full 200 years) can be compared with Fig. 9, which shows the 50-year (left column) and 100-year (right column) responses. The 150-year responses are not shown but are similar to 200-year responses in Fig. 6a-d. Table 1 (CAM4 LF lines) shows spatial correlations and LF+ and LF- RMS errors in the North Pacific-North America sector (PNA region) and North Atlantic-Europe sectors averaged over 200, 150, 100, and 50 years. In Figs. 6a, b and 9a, b, $\mathrm{e}, \mathrm{f}$, a symmetric PNA response to LF+ or LF- forcing is robust in all periods, and in Table 1 the spatial correlations in that region only slightly improve from -0.92 to -0.96 as the simulation increases from 50 to 200 years, although RMS anomalies diminish with increasing length (a longer simulation should result in smoother patterns). As in the 200-year period, negative NAO-like responses in Fig. 9c, g are opposite to those in observations (Fig. 3c, g). The nonlinear responses in Figs. 6d and 9d, h are erratic and insignificant for NAO (most evident at 100 years with almost no response in the North Atlantic at 200 years), and uncertain for PNA (a weak pattern with three out of four centers is seen at 200 years). The above results suggest that at least 100-200 years of simulations in CAM4 may be needed in order to confirm a robust PNA nonlinear response.

\subsection{Atmospheric responses to low frequency tropical Pacific forcing}

In Fig. 7, both models have quite similar tropical precipitation responses over the central/eastern Pacific, but show larger intermodel differences in the region 40E-150E. Several studies have shown that this region is the source of considerable nonlinearity (Molteni et al. 2015; Fletcher and Kushner 2011; Barsugli et al. 2006). Fletcher and Kushner
(2013) report large differences in the extratropical response to tropical forcing between the CAM4 and GFDL-AM2 models, and part of the differing response stemmed from forcing in the tropical western Pacific. To focus on impacts of LF Tropical Pacific (LFTP) forcing, here we conduct experiments with the CAM4 model where the LF SST anomalies are prescribed only in the Tropical Pacific region indicated by the rectangular box in Fig. 1a.

Figures 10 and 11 show responses of atmospheric fields of SAT, Z500 and precipitation to strong LFTP forcing simulations that correspond to CAM4 strong LF forcing responses in the left columns of Figs. 5, 6 and 7. These responses are in general similar to the LF forcing runs, indicating that LF tropical Pacific forcing plays a dominant role in total responses to LF forcing. However, in Fig. 10f, the Z500 response to LFTP - forcing in the North Pacific has a maximum value of $30 \mathrm{~m}$, compared to $15 \mathrm{~m}$ for the LF- forcing in Fig. 6b. In Fig. 10f, a significant NAO-like response is simulated in the LFTP- forcing. In Fig. 10g, a significant negative linear NAO-like response to LFTP forcing is simulated which is opposite to the corresponding observed feature in Fig. 3c. In Fig. 10h a weaker but still significant nonlinear NAO response emerges which reproduces the corresponding observed feature in Fig. 3d, h. Note that in Fig. 6f, h, GFDL simulates a less significant NAO-like response in the LF- forcing and a nonlinear NAO response. In addition, observed Z500 responses over mid-latitude Eurasia include a positive response to $\mathrm{LF}+$, a negative response to $\mathrm{LF}-$, and a positive linear response (Fig. 3a-c), and these are approximately reproduced in the LFTP forcing simulations (Fig. 10e-g), but not in the LF forcing simulations (Fig. 6a-c). In Figs. 2a, b and 10a-d, there are similar observed (strong LF months) and simulated (strong LFTP forcing) SAT responses over Eurasia, including large areas of significant warming responses to LF+ or LFTP+ and cooling responses to LF- or LFTP-, and large areas of significant warming linear responses.

Throughout the tropics $\left(20^{\circ} \mathrm{S}-20^{\circ} \mathrm{N}, 0-360^{\circ} \mathrm{E}\right)$, spatial correlation coefficients between LFTP+ and LFTP- precipitation anomalies are -0.81 , indicating a similar dipole pattern in Fig. 11a, b. In Fig. 11d, the main nonlinearity of tropical rainfall reflects a stronger rainfall response to LFTP+ than LFTP - forcing over the central and western Pacific, similar to the GFDL nonlinear response in Fig. $7 \mathrm{~h}$. In Fig. 12a-d, a dipole-like positive NAO response of EKE is especially evident with LFTP- forcing and a similar nonlinear response is simulated over the North Atlantic. The strong transient response to LFTP- forcing over the North Atlantic explains the significant NAO-like 300-hPa LFTP - response, linear negative NAO height tendencies and positive nonlinear NAO-like height tendencies in Fig. 12f-h. This suggests that a negative linear NAO response and a positive nonlinear NAO response to LFTP 
(a) CAM4 50years Z500 (LF+)

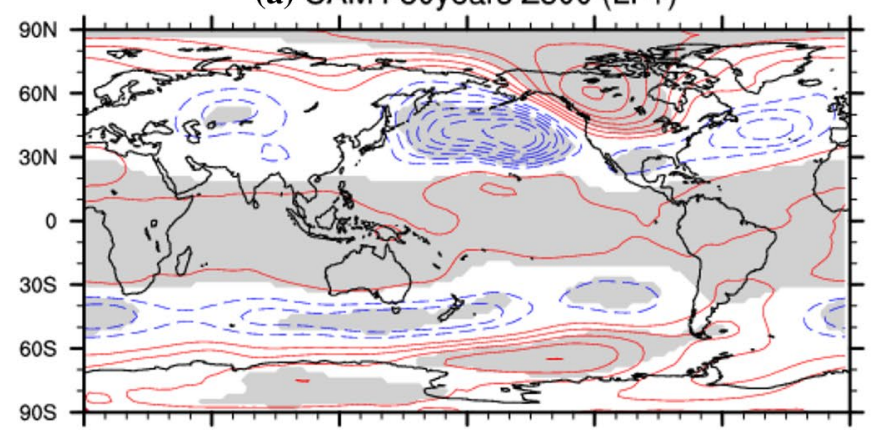

(b) CAM4 50years Z500 (LF-)

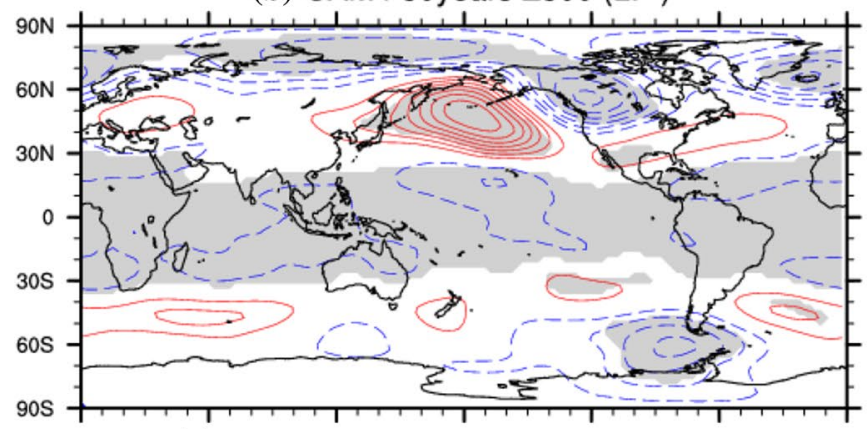

(c) CAM4 50years Z500 (LF+ minus LF-)

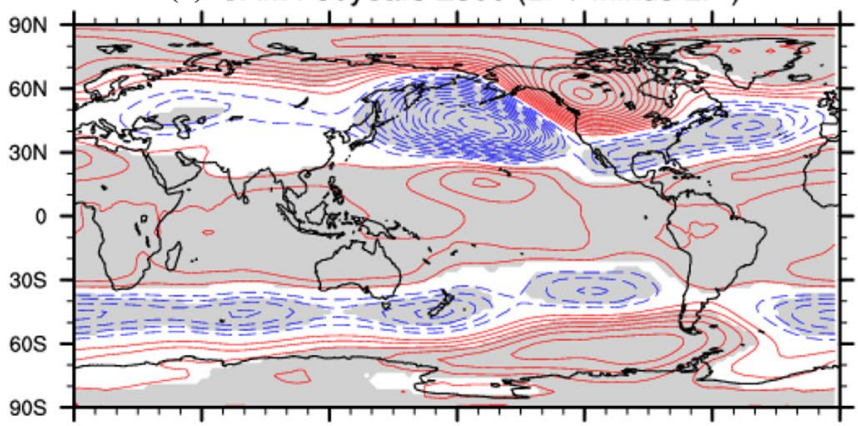

(d) CAM4 50years Z500 (LF+ plus LF-)

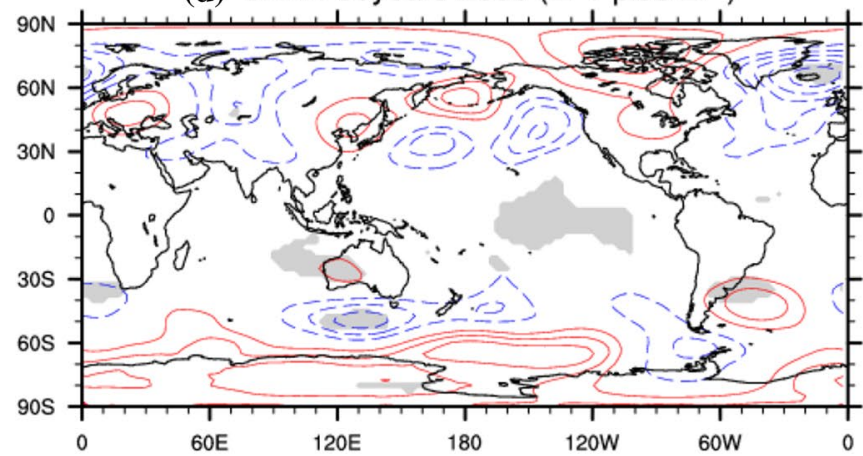

(e) CAM4 100years Z500 (LF+)

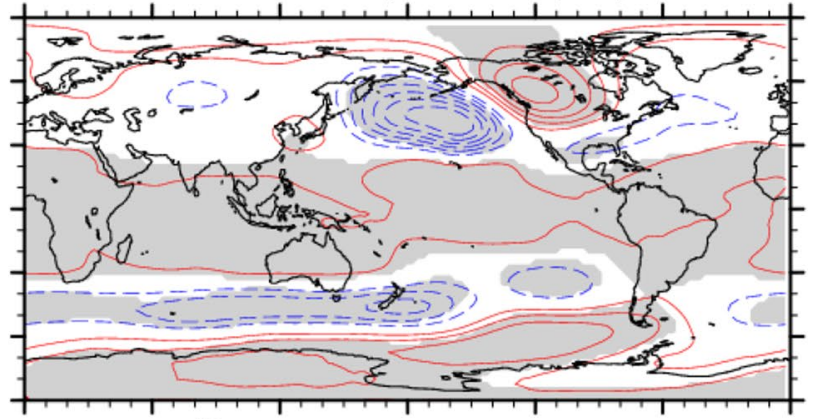

(f) CAM4 100years Z500 (LF-)

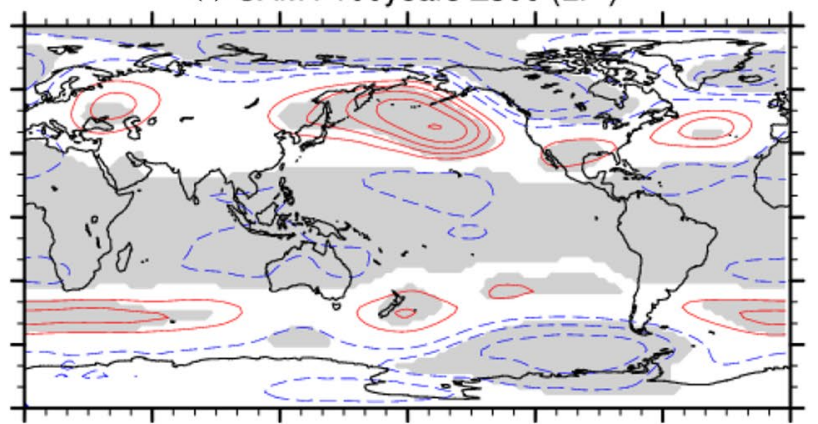

(g) CAM4 100years Z500 (LF+ minus LF-)

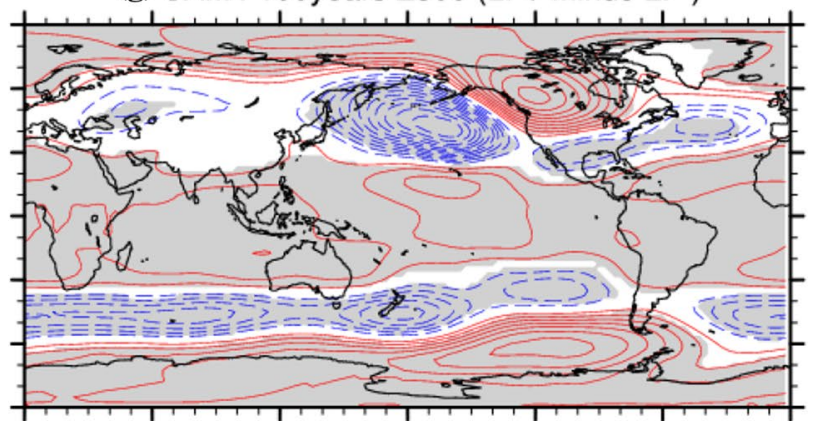

(h) CAM4 100years Z500 (LF+ plus LF-)

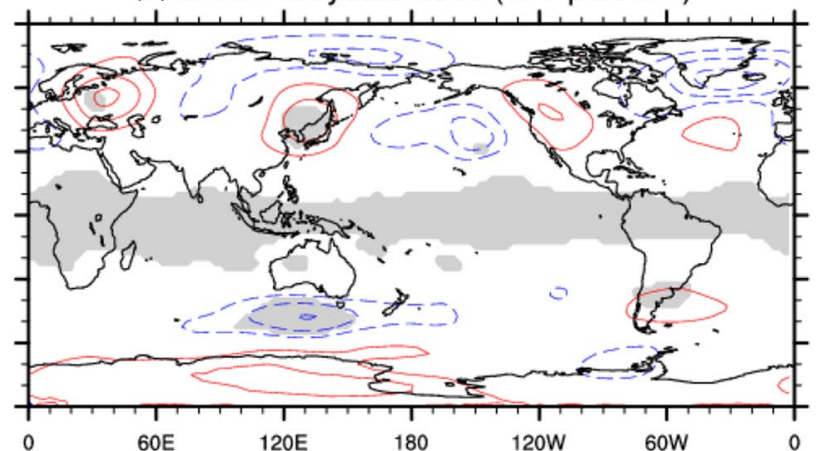

Fig. 9 Same as Fig. 6a-d, but for DJFM Z500 anomalies in the CAM4 simulation based on the first 50 and 100 years of the 200-year simulation, which is shown in Fig. 6a-d

forcing results from both nonlinearity of western tropical Pacific rainfall responses induced by LFTP+ forcing and stronger transient eddy feedbacks over the North Atlantic associated with LFTP- forcing. Similar NAO-like Z500 
(a) CAM4 SAT (LFTP+)

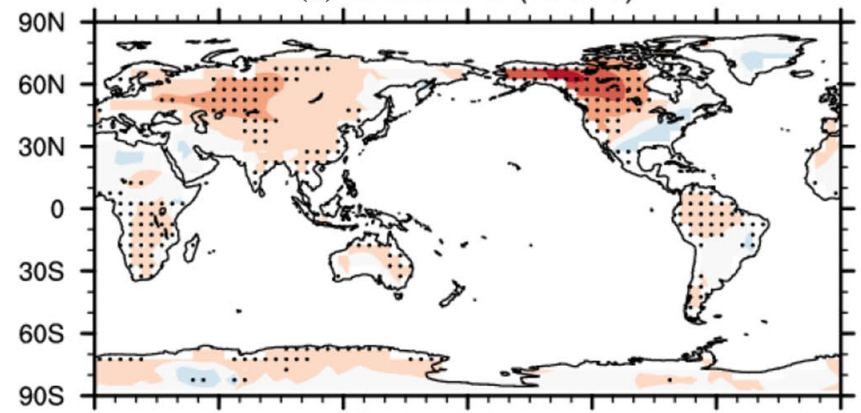

(b) CAM4 SAT (LFTP-)

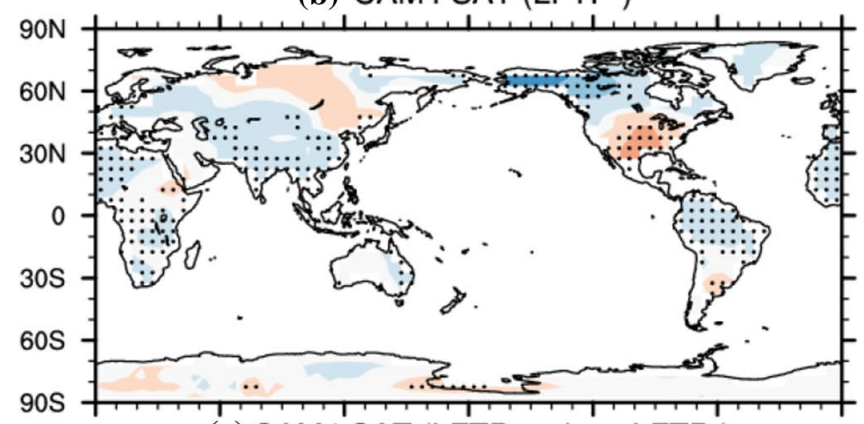

(c) CAM4 SAT (LFTP + minus LFTP-)

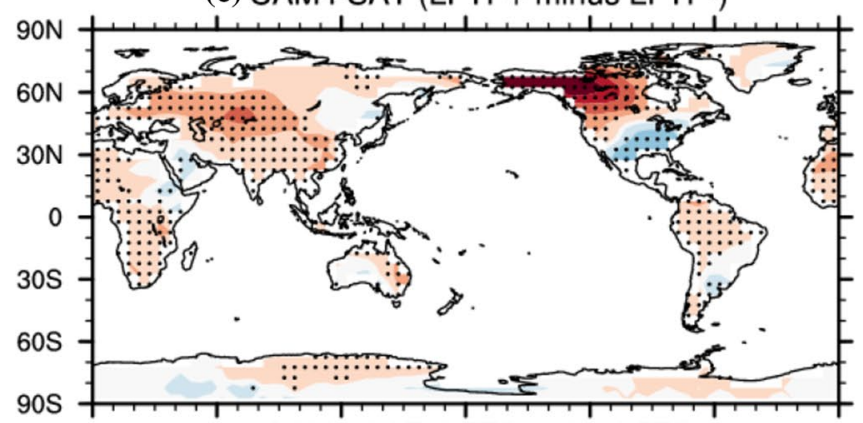

(d) CAM4 SAT (LFTP+ plus LFTP-)

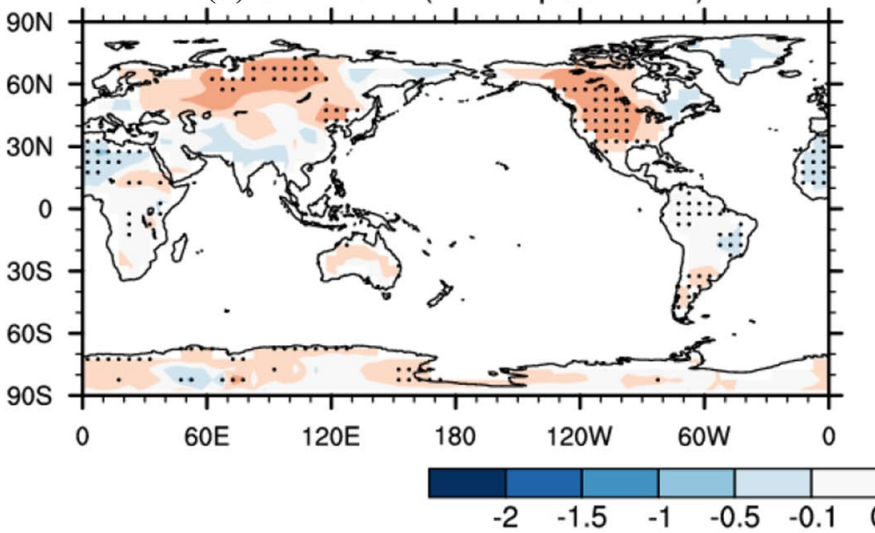

Fig. 10 Responses of SAT (left column) and Z500 (right) anomalies to strong IPO/PDO-like low frequency SST anomalies over the Tropical Pacific (box in Fig. 1a, referred to as LFTP forcing) simulated in CAM4. a, e Strong warm (LFTP+) forcing, and b, $\mathbf{f}$ strong cold (LFTP-) forcing. $\mathbf{c}, \mathbf{g}$ Linear component of the SAT anomalies (e) CAM4 Z500 (LFTP+)

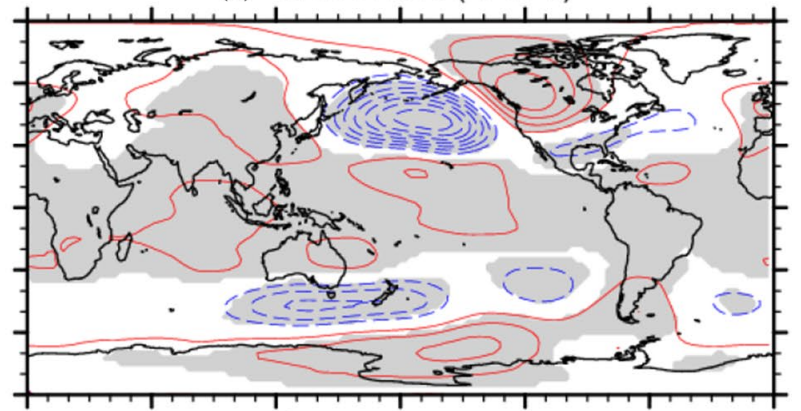

(f) CAM4 Z500 (LFTP-)

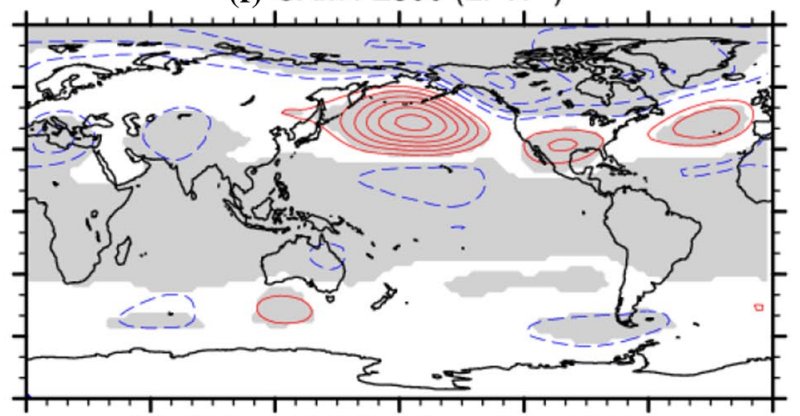

(g) CAM4 Z500 (LFTP+ minus LFTP-)

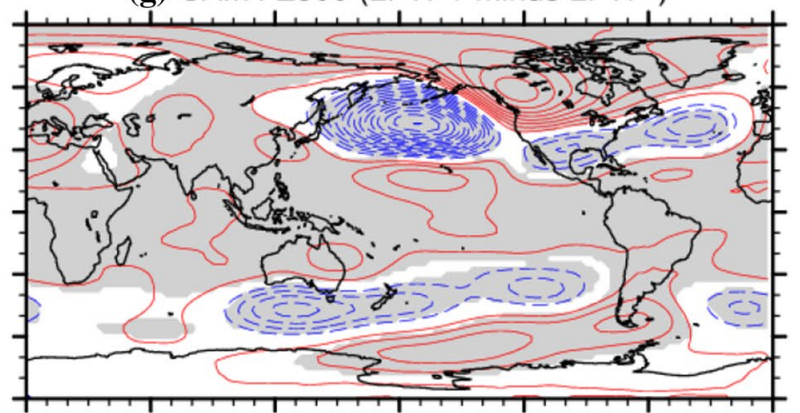

(h) CAM4 Z500 (LFTP+ plus LFTP-)

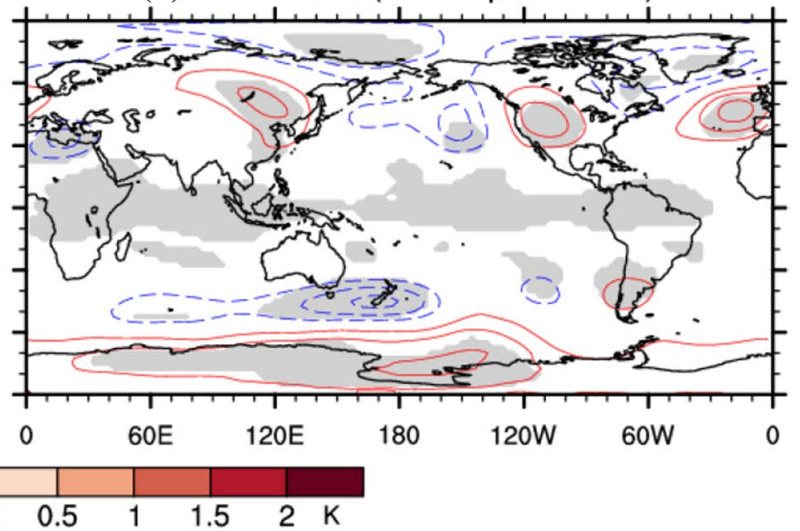

as estimated by the difference $\mathbf{a}$ minus $\mathbf{b}$ or $\mathbf{e}$ minus $\mathbf{f}$. $\mathbf{d}, \mathbf{h}$ Nonlinear component of the SAT anomalies, as estimated by the sum a plus $\mathbf{b}$, or e plus f. The black dots (left column) or gray shaded areas (right column) denote local statistical significance of values at the $95 \%$ confidence level 


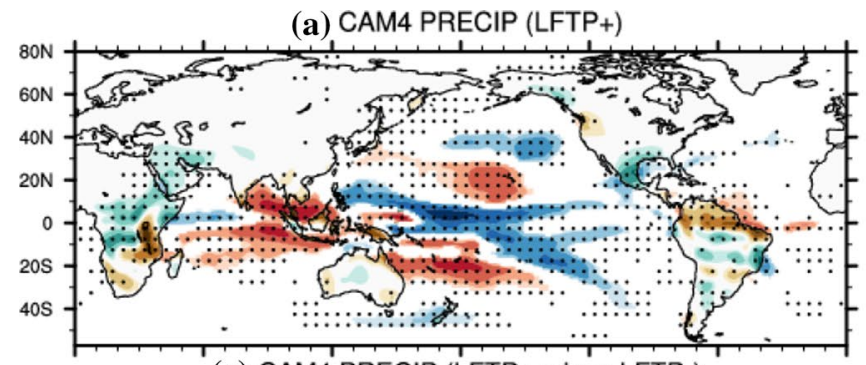

(c) CAM4 PRECIP (LFTP+ minus LFTP-)
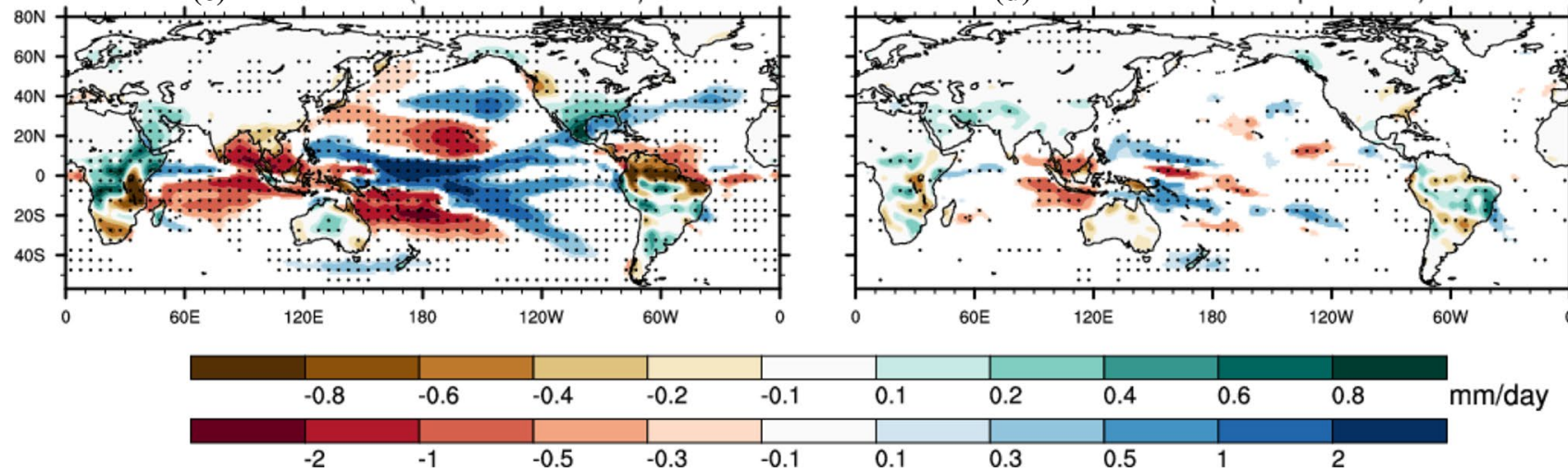

Fig. 11 Same as Fig. 10, but for DJFM precipitation anomalies (mm/day). Note that green or blue shading indicates a wet anomaly, and the ocean color bar has larger anomaly intervals than the land color bar

patterns in Fig. 9b, $\mathrm{f}$ indicate a strong transient response in the North Atlantic to tropical LF- and LFTP- forcing.

\section{Summary and conclusions}

We have assessed the observed and simulated DJFM winter atmospheric responses to strong positive and negative phases of IPO/PDO-like LF SST forcing. In addition to significant extratropical PNA-like linear components of Z500 anomalies reported before (Mantua et al. 1997), in the observations from winters 1949-2014 we also find a Southern Annularlike linear Z500 response in the $\mathrm{SH}$, a significant NAO-like Z500 response in the North Atlantic-Europe sector, and a dipole-like response with a positive Z500 anomaly over East Asia centered near Lake Baikal and a negative Z500 anomaly over Eurasia high latitudes and the adjacent Arctic Ocean. The dipole is the underlying cause of the large warming linear response of northern Eurasian surface temperatures. In addition, in the observations we find a PNAlike nonlinear Z500 response with large negative/positive anomalies in coastal western/eastern North America, and a significant NAO-like nonlinear component of Z500 anomalies in the NH. The above PNA and dipole also appear in the linear Z500 responses to LF forcing in 1904-2014, indicating a robust impact on North America and Eurasian climate changes related to LF SST forcing. The LF index has exhibited frequent extreme negative phases since 2000 (Fig. 1b), indicating that winter cold surges over northern Eurasia might be associated with LF SST forcing in recent decades.

Through AGCM simulations using the CAM4 and GFDL models, we demonstrate that almost all aspects of observed linear and nonlinear responses are reproducible in the Pacific-North American sector, including the PNA-like circulation responses, and the associated significant warming temperature anomaly over northeast North America and wet precipitation anomaly over southern North America. In addition, the significant PNA nonlinear responses are also reproducible in the strong LF experiments in both models and the strong LFTP experiment that we performed using CAM4. Nonlinear PNA responses to LF or LFTP forcing result from both nonlinearity of western tropical Pacific rainfall responses and transient eddy feedbacks in the extratropics. The numerical results demonstrate that PNA nonlinear responses in the observations might be real atmosphere phenomena. A nonlinear PNA response explains a significant nonlinear warm response over northeast North America to strong LF SST forcing.

The predominant observed significant linear warming SAT response and linear decreasing precipitation responses over most southern land areas with strong LF forcing are also generally reproduced in the simulations of both AGCMs. However, the NAO-like response to strong LF+ SST forcing in observations and the NAO linear response to LF SST forcing are not reproduced in the CAM4 200-year simulation or the GFDL 50-yr simulation. A significant observed NAO 
(a) CAM4 EKE (LFTP+)

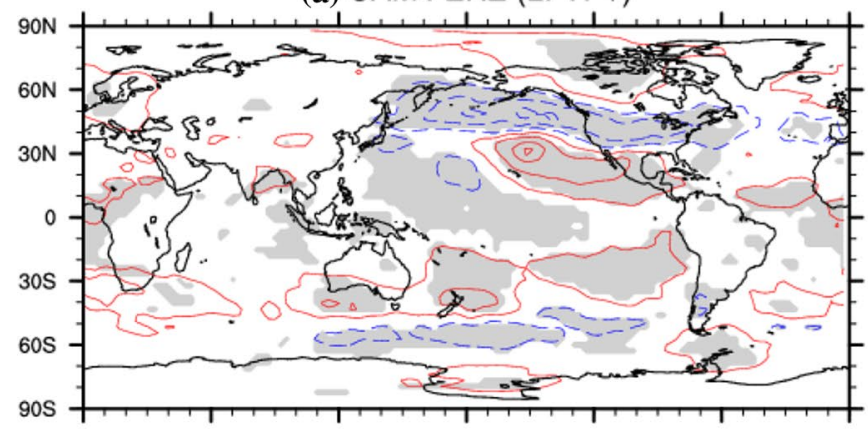

(b) CAM4 EKE (LFTP-)

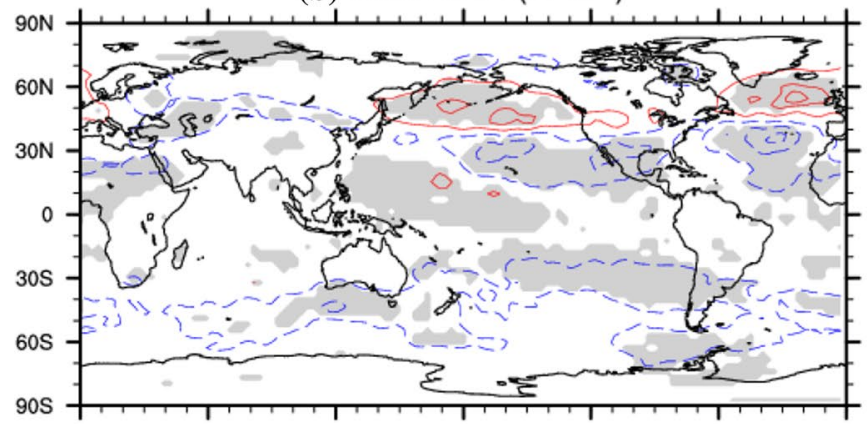

(c) CAM4 EKE (LFTP+ minus LFTP-)

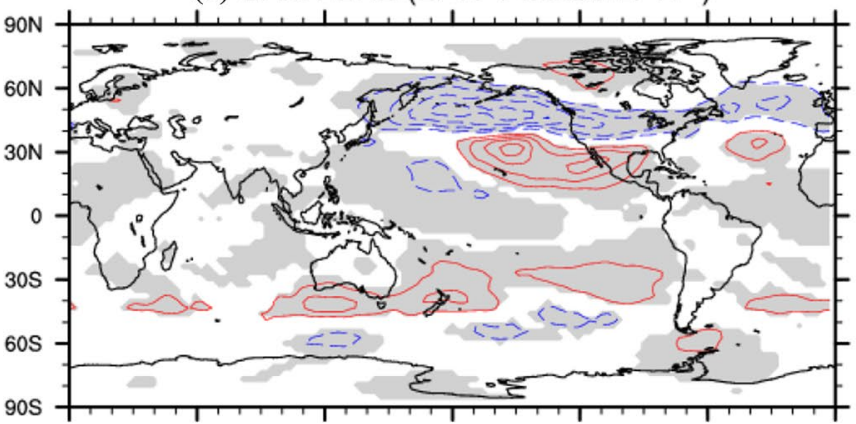

(d) CAM4 EKE (LFTP+ plus LFTP-)

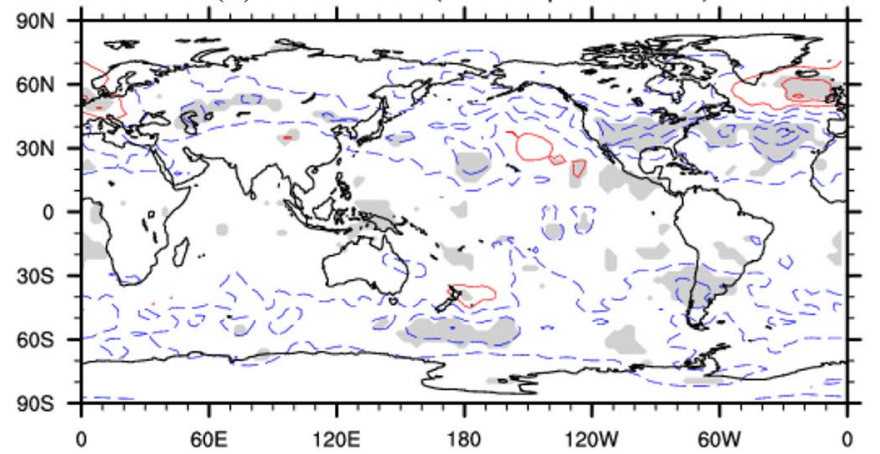

(e)CAM4 Z300 Tendencies (LFTP+)

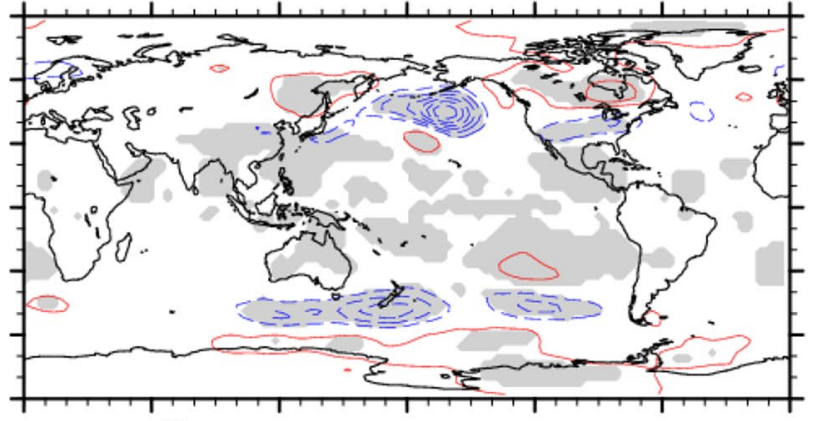

(f) CAM4 Z300 Tendencies (LFTP-)

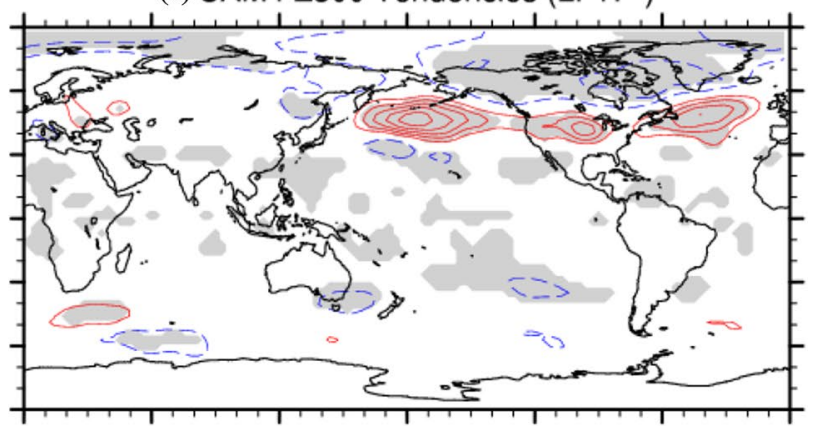

(g) CAM4 Z300 Tendencies (LFTP+ minus LFTP-)

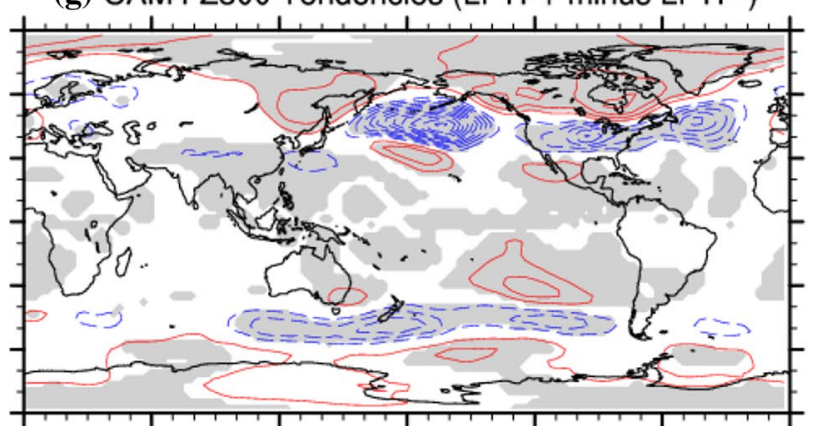

(h) CAM4 Z300 Tendencies (LFTP+ plus LFTP-)

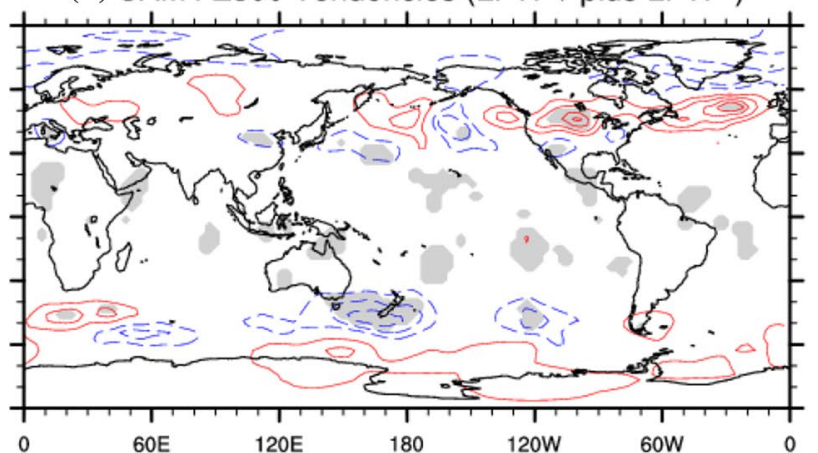

Fig. 12 Same as Fig. 10, but for (left column) DJFM eddy kinetic energy (EKE, $\mathrm{m}^{2} \mathrm{~s}^{-2}$, contour interval $1 \mathrm{~m}^{2} \mathrm{~s}^{-2}$ ), and (right column) $300 \mathrm{hPa}$ height tendencies $\left(\mathrm{m} \mathrm{s}^{-1}\right.$, contour interval $\left.0.5 \times 1 \mathrm{e}^{-5} \mathrm{~m} \mathrm{~s}^{-1}\right)$

response to strong LF- SST forcing is found in 1904-2014, but is not evident in 1949-2014. This significant NAO response to LF- forcing is reproduced by CAM4 in 50-yr and 100 -year simulations, but not in 200-year simulations. This indicates that sampling issues might play an important role in responses over the North Atlantic-European sector to LF SST forcing in both observations and simulations. Overall, there is considerable inconsistency in atmospheric responses over the North Atlantic-European sector to LF forcing among observations, and CAM4 and GFDL simulations. 
Some studies indicate that skillful decadal predictions of climate change over many land regions, such as North and South America, Asia, Africa and Australia, require accurate accounting for SST variations associated with the PDO/IPO (Power et al. 1999; Deser et al. 2004; Smith et al. 2012; Meehl et al. 2013, 2014). When estimates of the limit of climate predictability are developed for climate models, the physical processes associated with Pacific and Atlantic decadal variability of SSTs should be correctly represented to gain confidence in forecasts. The observed linear responses to strong LF events over the PNA region and most southern land areas are well reproduced in both CAM4 and GFDL model simulations (Figs. 3c, 6c, g). This indicates that AGCM simulations, even without a coupled ocean model, are potentially adequate to examine decadal predictability of climate changes over North America and southern lands associated with PDO/IPO-like interdecadal Pacific SST variability. In observations, linear warming responses to both strong and moderate LF events are found over Eurasia (responses to moderate LF forcing are not shown), in contrast to an insignificant cooling response simulated in both models and a weak warming response to LFTP forcing in CAM4. This suggests that these AGCMs might omit or do not properly simulate some key physical processes related to impacts of PDO/IPO-like interdecadal Pacific SST variability on Eurasian winter climate changes, such as recent cold winter temperature trends (Cohen et al. 2012). Therefore, these models are unlikely to produce useful climate predictions over Eurasia at interdecadal time scales since the observed and simulated linear responses over northern Eurasia and the adjacent eastern Arctic to strong LF events are opposite and not consistent. Ongoing research is being performed to examine the associations between Pacific decadal SST variability and regional climate changes over worldwide land areas in the CMIP5 pre-industrial and historical simulations from various models.

Acknowledgements We acknowledge the U.S. Climate Variability and Predictability (CLIVAR) Working Group on Drought for producing and making available model outputs. NCEP reanalysis, MLOST and GPCC datasets are provided by the NOAA/OAR/ESRL PSD from their Web site at http://www.esrl.noaa.gov/psd/. This work is funded by the National Key Scientific Research Plan of China (Grant 2012CB956002) and the National Natural Science Foundation of China (Grants 41075052 and 41375076), and also supported by the Jiangsu Collaborative Innovation Center for Climate Change and CMA-NJU Joint Laboratory for Climate Prediction Studies. Aixue Hu is supported by the Regional and Global Model Analysis Program (RGMA) of the U.S. Department of the Energy's Office of Science (BER), Cooperative Agreement No. DE-FC02-97ER62402. We are grateful for the insightful and constructive comments from three anonymous reviewers.

Open Access This article is distributed under the terms of the Creative Commons Attribution 4.0 International License (http://creativeco mmons.org/licenses/by/4.0/), which permits unrestricted use, distribution, and reproduction in any medium, provided you give appropriate credit to the original author(s) and the source, provide a link to the Creative Commons license, and indicate if changes were made.

\section{References}

Abid MA, Kang IS, Almazroui M, Kucharski F (2015) Contribution of synoptic transients to the potential predictability of PNA circulation anomalies: El Niño versus La Niña. J Clim 28:8347-8362

Andreoli RV, Kayano MT (2005) ENSO-related rainfall anomalies in South America and associated circulation features during warm and cold Pacific decadal oscillation regimes. Int J Climatol 25:2017-2030

Arblaster JM, Meehl GA, Moore AM (2002) Interdecadal modulation of Australian rainfall. Clim Dyn 18:519-531

Barsugli JJ, Shin SI, Sardeshmukh PD (2006) Sensitivity of global warming to the pattern of tropical ocean warming. Clim Dyn 27:483-492

Bell CJ, Gray LJ, Charlton-Perez AJ, Joshi MM, Scaife AA (2009) Stratospheric communication of El Nino teleconnections to European winter. J Clim 22:4083-4096

Bretherton CS, Widmann M, Dymnikov VP, Wallace JM, Bladé I (1999) The effective number of spatial degrees of freedom of a time-varying field. J Clim 12:1990-2009

Bronnimann S (2007) Impact of El Nino-Southern Oscillation on European climate. Rev Geophys 45:RG3003. https://doi. org/10.1029/2006RG000199

Cagnazzo C, Manzini E (2009) Impact of the stratosphere on the winter tropospheric teleconnections between ENSO and the North Atlantic and European region. J Clim 22:1223-1238

Cohen JL, Furtado JC, Barlow MA, Alexeev VA, Cherry JE (2012) Arctic warming, increasing snow cover and widespread boreal winter cooling. Environ Res Lett 7:014007

Compo GP et al (2011) The twentieth century reanalysis project. Q J R Meteorol Soc 137:1-28

Dai A (2013) The influence of the inter-decadal Pacific oscillation on US precipitation during 1923-2010. Clim Dyn 41:633-646

Delworth et al (2006) GFDL's CM2 global coupled climate models-Part 1: formulation and simulation characteristics. J Clim 19:643-674

Deser C, Phillips AS, Hurrell JM (2004) Pacific interdecadal climate variability: Linkages between the tropics and the North Pacific during boreal winter since 1900. J Clim 17:3109-3124

DeWeaver E, Nigam S (2002) Linearity in ENSO's atmospheric response. J Clim 15:2446-2461

Dong L, Dai A (2015) The influence of the Interdecadal Pacific Oscillation on temperature and precipitation over the globe. Clim Dyn 45:2667-2681

Fletcher CG, Kushner PJ (2011) The role of linear interference in the annular mode response to tropical SST forcing. J Clim 24:778-794

Fletcher CG, Kushner PJ (2013) Linear interference and the Northern Annular Mode response to tropical SST forcing: sensitivity to model configuration. J Geophys Res 118:4267-4279

Folland CK et al (2002) Relative influences of the Interdecadal Pacific Oscillation and ENSO on the South Pacific Convergence Zone. Geophys Res Lett 29(13):1643. https://doi.org/10.1029/2001GL014201

Gershunov A, Barnett TP (1998) ENSO influence on intraseasonal extreme rainfall and temperature frequencies in the contiguous United States: observations and model results. J Clim 11:1575-1586

Gershunov A, Cayan D (2003) Heavy daily precipitation frequency over the contiguous United States: sources of climatic variability and seasonal predictability. J Clim 16:2752-2765

Henley BJ, Gergis J, Karoly DJ, Power SB, Kennedy J, Folland CK (2015) A Tripole Index for the Interdecadal Pacific Oscillation. Clim Dyn 45:3077-3090

Hoell A, Funk C, Barlow M (2015) The forcing of southwestern Asia teleconnections by low-frequency sea surface temperature variability during boreal winter. J Clim 28:1511-1526 
Hoerling MP, Kumar A, Zhang M (1997) El Niño, La Niña, and the nonlinearity of their teleconnections. J Clim 10:1769-1786

Hoerling MP, Kumar A, Xu T (2001) Robustness of the nonlinear climate response to ENSO's extreme phases. J Clim 14:1277-1293

Horel JD, Wallace JM (1981) Planetary-scale atmospheric phenomena associated with the Southern Oscillation. Mon Weather Rev 109:813-829

Hoskins BJ, Karoly DJ (1981) The steady linear response of a spherical atmosphere to thermal and orographic forcing. J Atmos Sci 38:1179-1196

Ineson S, Scaife AA (2009) The role of the stratosphere in the European climate response to El Nino. Nat Geosci 2:32-36

Kalnay E et al (1996) The NCEP/NCAR 40-year reanalysis project. Bull Am Meteorol Soc 77:437-471

Kosaka Y, Xie SP (2013) Recent global-warming hiatus tied to equatorial Pacific surface cooling. Nature 501:403-407

Kushnir Y, Lau NC (1992) The general circulation model response to a North Pacific SST anomaly: dependence on time scale and pattern polarity. J Clim 5:271-283

Lau NC (1988) Variability in the observed midlatitude storm tracks in relation to low-frequency changes in the circulation pattern. $\mathrm{J}$ Atmos Sci 45:2718-2743

Lin H, Derome J (2004) Nonlinearity of the extratropical response to tropical forcing. J Clim 17:2597-2608

Lin H, Derome J, Brunet G (2007) The nonlinear transient atmospheric response to tropical forcing. J Clim 20:5642-5665

Mantua NJ et al (1997) A Pacific interdecadal climate oscillation with impacts on salmon production. Bull Am Meteorol Soc 78:1069-1079

McCabe GJ, Dettinger MD (1999) Decadal variations in the strength of ENSO teleconnections with precipitation in the western United States. Int J Climatol 19:1399-1410

Meehl GA, Hu A (2006) Megadroughts in the Indian monsoon region and southwest North America and a mechanism for associated multidecadal Pacific sea surface temperature anomalies. J Clim 19:1605-1623

Meehl GA, Hu A, Arblaster JM, Fasullo J, Trenberth KE (2013) Externally forced and internally generated decadal climate variability associated with the Interdecadal Pacific Oscillation. J Clim 26:7298-7310

Meehl GA et al (2014) Decadal climate prediction. An Update from the Trenches. Bull Am Meteorol Soc 95:243-267

Molteni F, Stockdale TN, Vitart F (2015) Understanding and modelling extratropical teleconnections with the Indo-Pacific region during the northern winter. Clim Dyn 45:3119-3140

Montroy DL, Richman MB, Lamb PJ (1998) Observed nonlinearities of monthly teleconnections between tropical Pacific sea surface temperature anomalies and central and eastern North American precipitation. J Clim 11:1812-1835

Neale R, Richter J, Park S, Lauritzen PH, Vavrus SJ, Rasch PJ, Zhang M (2013) The mean climate of the Community Atmosphere Model (CAM4) in forced SST and fully coupled experiments. J Clim 26:5150-5168

Newman M, Compo GP, Alexander MA (2003) ENSO-forced variability of the Pacific Decadal Oscillation. J Clim 16:3853-3857

Newman et al (2016) The Pacific Decadal Oscillation, revisited. J Clim 29:4399-4427

Pitcher EJ et al (1988) The effect of North Pacific sea surface temperature anomalies on the January climate of a general circulation model. J Atmos Sci 45:173-188

Power S, Casey T, Folland C, Colman A, Mehta V (1999) Inter-decadal modulation of the impact of ENSO on Australia. Clim Dyn $15: 319-324$
Pozo-Vazquez D, Esteban-Parra MJ, Rodrigo FS, Castro-Diez Y (2001) The association between ENSO and winter atmospheric circulation and temperature in the North Atlantic region. J Clim 14:3408-3420

Rayner NA et al (2003) Global analyses of SST, sea ice, and night marine air temperature since the late nineteenth century. J Geophys Res 108:4407. https://doi.org/10.1029/2002JD002670

Salinger MJ, Renwick JA, Mullan AB (2001) Interdecadal Pacific Oscillation and South Pacific climate. Int J Climatol 21:1705-1721

Sardeshmukh PD, Hoskins BJ (1988) The generation of global rotational flow by steady idealized tropical divergence. J Atmos Sci 45:1228-1251

Schneider U et al (2013) GPCC's new land surface precipitation climatology based on quality-controlled in situ data and its role in quantifying the global water cycle. Theor Appl Climatol. https:// doi.org/10.1007/s00704-013-0860-x

Schubert S, Gutzler D, Wang H et al (2009) A US CLIVAR project to assess and compare the responses of global climate models to drought-related SST forcing patterns: overview and result. J Clim 22:5251-5272

Simmons AJ (1982) The forcing of stationary wave motion by tropical diabatic heating. Q J R Meteorol Soc 108:503-534

Smith TM, Reynolds RW, Peterson TC, Lawrimore J (2008) Improvements to NOAA's historical merged land-ocean surface temperature analysis (1880-2006). J Clim 21:2283-2293

Smith DM et al (2012) Real-time multi-model decadal climate predictions. Clim Dyn 41:2875-2888. https://doi.org/10.1007/s0038 2-012-1600-0

Thompson DWJ, Wallace JM (1998) The Arctic Oscillation signature in the wintertime geopotential height and temperature fields. Geophys Res Lett 25:1297-1300

Ting M, Hoerling MP (1993) Dynamics of stationary wave anomalies during the 1986/87 El Niño. Clim Dyn 9:147-164

Trenberth KE, Hurrell JM (1994) Decadal atmosphere-ocean variations in the Pacific. Clim Dyn 9:303-319

Trenberth KE et al (2014) Seasonal aspects of the recent pause in surface warming. Nat Clim Change 4:911-916

von Storch H, Zwiers FW (1999) Statistical analysis in climate research. Cambridge University Press, Cambridge

Wallace JM, Gutzler DS (1981) Teleconnections in the geopotential height field during the Northern Hemisphere winter. Mon Weather Rev 109:784-812

Wang L, Chen W, Huang R (2008) Interdecadal modulation of PDO on the impact of ENSO on the East Asian winter monsoon. Geophys Res Lett 35:L20702

Wang S et al (2014) Combined effects of the Pacific decadal oscillation and El Niño-Southern oscillation on global land dry-wet changes. Sci Rep 4:6651

Wu A, Hsieh WW (2004) The nonlinear Northern Hemisphere atmospheric response to ENSO. Geophys Res Lett 31:L02203

Wu A, Hsieh WW, Shabbar A (2005) The nonlinear patterns of North American winter temperature and precipitation associated with ENSO. J Clim 18:1736-1752

Wu B, Li T, Zhou T (2010) Asymmetry of atmospheric circulation anomalies over the western North Pacific between El Niño and La Niña. J Clim 23:4087-4822

Zhang Y, Wallace JM, Battisti DS (1997) ENSO-like interdecadal variability: 1900-93. J Clim 10:1004-1020

Zhang T, Hoerling MP, Perlwitz J, Sun DZ, Murray D (2011) Physics of U.S. surface temperature response to ENSO. J Clim 24:4874-4887

Zhang T, Perlwitz J, Hoerling MP (2014) What is responsible for the strong observed asymmetry in teleconnections between El Niño and La Niña? Geophys Res Lett 41:1019-1025. https://doi. org/10.1002/2013GL058964 